\title{
Seasonal evolution of the surface layer heat balance in the eastern subtropical Indian Ocean
}

\author{
A. Cyriac ${ }^{1,2 *}$, M. J. McPhaden ${ }^{3}$, H. E. Phillips ${ }^{1}$, N. L. Bindoff ${ }^{1,4,5,6}$, M. Feng \\ 7,8 \\ ${ }^{1}$ Institute for Marine and Antarctic Studies, University of Tasmania, Hobart, Australia \\ ${ }^{2}$ ARC Centre of Excellence for Climate System Science, Hobart, Australia \\ ${ }^{3}$ NOAA/Pacific Marine Environmental Laboratory, Seattle, Washington, USA \\ ${ }^{4} \mathrm{ARC}$ Centre of Excellence in Climate Extremes, Hobart, Australia \\ ${ }^{5}$ Antarctic Climate and Ecosystems CRC, Hobart, Australia \\ ${ }^{6}$ CSIRO Marine and Atmospheric Research, Hobart, Australia \\ ${ }^{7}$ CSIRO Oceans and Atmosphere, IOMRC, Crawley, Western Australia, Australia \\ ${ }^{8}$ Centre for Southern Hemisphere Oceans Research, Hobart, Tasmania, Australia
}

\section{Key Points:}

- The first moored time series measurements of air-sea fluxes in the eastern subtropical Indian Ocean are presented.

- The seasonal cycle of the surface mixed layer heat budget is primarily influenced by surface net heat flux and secondarily by entrainment.

- Horizontal heat advection is dominated by mesoscale eddy fluxes and at times also contribute to the heat balance.

\footnotetext{
*Institute for Marine and Antarctic Studies, University of Tasmania

Corresponding author: Ajitha Cyriac, ajitha.cyriac@utas.edu.au
} 


\section{Abstract}

The south Indian Ocean (SIO) is a region of strong air-sea heat loss due to the unique ocean circulation pattern influenced by the Indonesian Throughflow. In this study, the seasonal variation of the surface layer heat budget in the eastern SIO is investigated using 2 years of measurements from a mooring at $25^{\circ} \mathrm{S}, 100^{\circ} \mathrm{E}$, the only colocated upper ocean and surface meteorology time series in the subtropical Indian Ocean. The mooring data are combined with other in situ and satellite data to examine the role of air-sea fluxes and ocean heat transport on the evolution of mixed layer temperature using heat budget diagnostic models. Results show that on seasonal timescales, mixed layer heat storage in the eastern SIO is mostly balanced by a combination of surface fluxes and turbulent entrainment with a contribution from horizontal advection at times. Solar radiation dominates the seasonal cycle of net surface heat flux, which warms the mixed layer during austral summer (67 $\left.\mathrm{Wm}^{-2}\right)$ and cools it during austral winter $\left(-44 \mathrm{Wm}^{-2}\right)$. Entrainment is in good agreement with the heat budget residual for most of the year. Horizontal advection is spatially variable and appears to be dominated by the presence of mesoscale eddies and possibly annual and semi-annual Rossby waves propagating from the eastern boundary. Results from the 2-year mooring-based data analysis are in reasonably good agreement with a 12-year regional heat budget analysis around the mooring location using ocean reanalysis products.

\section{Plain Language Summary}

The Southeast Indian Ocean is a region where the ocean loses a lot of heat to the atmosphere. However, until now there have not been any direct measurements of the heat flux from ocean to atmosphere and the other data sets that we use to understand this exchange do not agree on its size. In this study, we use 2 years of measurements from a flux mooring deployed near $25^{\circ} \mathrm{S}, 100^{\circ} \mathrm{E}$, together with satellite data and model outputs to understand the seasonal changes in air-sea fluxes and the role of ocean currents in controlling ocean surface temperatures in the southeast Indian Ocean. We found that the amount of heat stored in the surface mixed layer of the ocean is primarily the result of a balance between heat fluxes across the air-sea interface and cooling of the surface ocean by mixing with deep water below. The heat transported by the ocean currents, is highly impacted by eddies and waves propagating from the coast of Western Australia, and at times also contributes to the heat balance in this region. The results of this study improve our understanding of how 
heat moves between the ocean and atmosphere to affect our climate and will help refine computer model projections of future climate change.

\section{Introduction}

The eastern South Indian Ocean (SIO) is a region of strong heat loss to the atmosphere (Josey, Kent, \& Taylor, 1999; Yu, Jin, \& Weller, 2007). The Indonesian Throughflow (ITF) brings warm surface water into the tropical Indian Ocean from the Pacific. A review of different modeling studies shows that the changes in ocean circulation associated with the ITF can influence the heat loss to the atmosphere in the SIO (Godfrey, 1996). The trade winds drive some of the warm water brought by the ITF to the south through Ekman drift (Godfrey, 1996; Schott \& McCreary, 2001). Since the overlying atmosphere is cooler south of $20^{\circ} \mathrm{S}$, this heat is lost to the atmosphere (Godfrey, 1996), resulting in deeper winter mixed layers in the SIO compared to other subtropical oceans (Schott \& McCreary, 2001). This loss of heat together with strong evaporation leading to high salinity in surface waters generates dense water that subducts into the thermocline (Zhang \& Talley, 1998). These subducted waters contribute to the downwelling branches of the southern cell and crossequatorial cell of the Indian Ocean's shallow meridional overturning circulation south of $20^{\circ} \mathrm{S}$ (Lee, 2004). The cold, subducted thermocline water will later return to the surface through the upwelling regions in the north Indian Ocean (Schott \& McCreary, 2001).

Reanalysis products disagree on the magnitude of the surface heat fluxes in the SIO (Yu et al., 2007). These differences can result in inaccurate heat budget terms especially in regional studies (Schott \& McCreary, 2001). A major reason for this difference is the lack of enough observations of air-sea fluxes to validate the reanalysis products (Josey et al., 1999; Fairall et al., 2010; Sun, Yu, \& Weller, 2003). To address this gap in observations, a Research Moored Array for African-Asian-Australian Monsoon Analysis and Prediction (RAMA) flux mooring (McPhaden et al., 2009) measuring air-sea fluxes was deployed in the eastern SIO to provide high temporal resolution data to constrain the air-sea fluxes there, and to examine the ocean-atmosphere coupling in this region.

The surface heat fluxes along with oceanic processes play an important role in the evolution of seasonal and interannual variations in sea surface temperature (SST) (Yu et al., 2007). The ocean circulation in the eastern SIO is dominated by the eastward flowing nearsurface geostrophic South Indian countercurrent (SICC) branches (Divakaran \& Brassington, 
2011; Menezes et al., 2014; Palastanga, van Leeuwen, Schouten, \& P. M. de Ruijter, 2007; Siedler, Rouault, \& Lutjeharms, 2006) and the poleward flowing Leeuwin Current (LC). The eastern SIO is rich in eddies from the LC (Fang \& Morrow, 2003) as well as from local shear instability (Jia, Wu, \& Qiu, 2011, Figure 1g-h) and by the occasional passage of sea level anomalies emanating from the eastern boundary with Rossby wave speed (Morrow \& Birol, 1998; Morrow, Birol, Griffin, \& Sudre, 2004). The LC is the only eastern boundary current where the ocean loses heat with comparable magnitudes to a western boundary current (Josey et al., 1999). This heat loss extends westward from the coast in association with the westward movement of LC eddies into the SICC (Domingues, Maltrud, Wijffels, Church, \& Tomczak, 2007; Feng, Biastoch, Boening, Caputi, \& Meyers, 2008; Morrow \& Birol, 1998; Morrow, Fang, Fieux, \& Molcard, 2003). Using an eddy resolving model, Feng et al. (2008) found that LC advection and air-sea fluxes are important for the mixed layer heat budget in the $\mathrm{LC}$ basin $\left(27^{\circ} \mathrm{S}-32^{\circ} \mathrm{S}, 100^{\circ} \mathrm{E}\right.$ to the coast) on both seasonal and interannual timescales. In recent decades, SST has been increasing in the LC region (Feng et al., 2008; Pearce \& Feng, 2007) possibly with some contribution from the increased frequency of Ningaloo Ninos, characterized by anomalous warm SSTs in the LC region (Feng et al., 2015). Such anomalous warming has a great impact on the marine ecosystem off the western coast of Australia (Feng, McPhaden, Xie, \& Hafner, 2013; Wernberg et al., 2013).

Here we analyze the seasonal cycle of mixed layer heat balance, using daily surface heat fluxes from the RAMA mooring deployed at $25^{\circ} \mathrm{S}, 100^{\circ} \mathrm{E}$, together with auxiliary data. The highly-resolved time series from this RAMA mooring represents the only time series of air-sea flux observations made in the subtropical SIO. We used data from two consecutive deployments at this location spanning from the end of August 2012 to November 2014 and a combination of in situ, satellite and reanalysis products, to estimate the mixed layer heat budget in the eastern SIO. By assuming that the errors in heat budget terms are small, the residual of the budget is attributed primarily to vertical entrainment and heat diffusion at the base of the mixed layer.

The paper is organized as follows. Section 2 describes the datasets used in this study. The mixed layer heat budget equations are discussed in section 3. Section 4 contains the results of the 2 year mixed layer heat balance using mooring data. Results of the 12 year analysis using TropFlux data is presented in section 5. Section 6 compares the results of this study with those of previous studies and also provides a summary. 


\section{Data}

The RAMA flux mooring at $25^{\circ} \mathrm{S}, 100^{\circ} \mathrm{E}$ recorded bulk atmospheric and oceanic variables that are used to compute surface fluxes and upper ocean variability for 27 months. We analyzed the mixed layer heat budget at the mooring location and also over a $2^{\circ} \times 2^{\circ}$ box around the mooring using satellite, Argo and reanalysis products, to supplement the mooring data where necessary. The reanalysis products allowed a calculation of the heat budget over a 12 year period to compare with the 2 year mooring period.

To provide spatial context for the mooring observations, Figure 1 presents a comparison of winter and summer conditions around the mooring based on Argo and reanalysis data. During austral winter, the eastern SIO loses more heat to the atmosphere $\left(\sim 200 \mathrm{Wm}^{-2}\right)$ compared to the heat gain during austral summer $\left(\sim 50-100 \mathrm{Wm}^{-2}\right)($ Figure $1 \mathrm{a}-\mathrm{d})$. The mooring is located in a haline frontal region with cool saltier waters towards the south and comparatively warm fresher waters in the north (Menezes et al., 2014, ; Figure 1e-f). The sea surface height (SSH) decreases towards the poles similar to the SST (Figure $1 \mathrm{~g}$-h) with larger SSH in the LC region compared to offshore. The sea level anomaly (SLA) is dominated by LC eddies during austral winter when the LC is stronger. The spatial variability of SLA is less in austral summer compared to that in austral winter, consistent with the seasonal cycle of the LC.

\subsection{Mooring data}

The RAMA mooring (Figure 1) was deployed in late August 2012, was recovered and redeployed in July 2013, and stopped transmitting in November 2014. The mooring was never recovered due to the unavailability of a ship capable of mooring work at the time.

The mooring recorded hourly measurements of ocean temperature, salinity, current speed and direction, wind speed and direction, air temperature and pressure, relative humidity, short wave and long wave radiation, and rainfall. Ocean temperature sensors were placed at depths of $1 \mathrm{~m}, 5 \mathrm{~m}, 10 \mathrm{~m}, 20 \mathrm{~m}, 40 \mathrm{~m}, 60 \mathrm{~m}, 80 \mathrm{~m}, 100 \mathrm{~m}, 120 \mathrm{~m}, 140 \mathrm{~m}, 180 \mathrm{~m}$, $300 \mathrm{~m}$, and $500 \mathrm{~m}$. Salinity was measured at $1 \mathrm{~m}, 10 \mathrm{~m}, 20 \mathrm{~m}, 40 \mathrm{~m}, 60 \mathrm{~m}, 100 \mathrm{~m}$ and 140 $\mathrm{m}$. There were no ocean current data from the first deployment. On the second, there was a point current meter located at $10 \mathrm{~m}$ depth. However, it only gave sporadic measurements between July 2013 and November 2014 which were not suitable to use in the calculations 

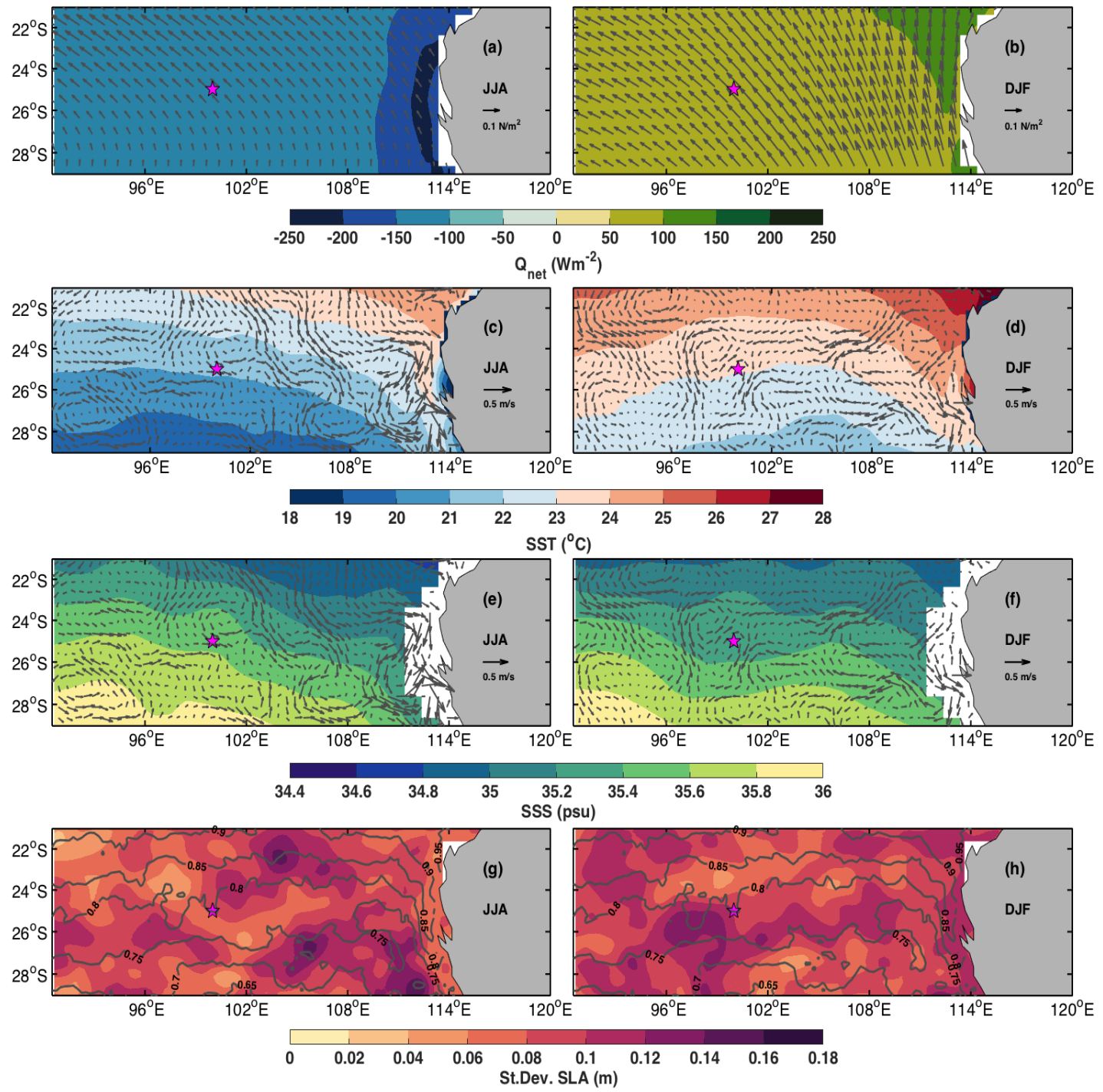

Figure 1. a-b) Climatology of net heat flux from TropFlux (overlaid with TropFlux wind stress), c-d) Reynolds SST and e-f) Sea Surface Salinity (SSS) from Argo (overlaid with OSCAR surface currents) during 2004 - 2015. g-h) The standard deviation of SLA from AVISO during $2004-2012$ overlaid with contours of mean dynamic topography (SSH) climatology for the period $1992-2012$. The left panels (a, c, e, g) are for austral winter and right panels (b, d, f, h) are for austral summer. The star shows the location of the RAMA mooring. Positive fluxes show heat gain by the ocean.

(supporting information Figure S1). These velocities were useful, though, in confirming that the OSCAR velocities were of realistic amplitude. 
The shortwave and longwave radiation, and precipitation were measured at $3.5 \mathrm{~m}$ above the sea surface. Wind speed and direction were measured at a height of $4 \mathrm{~m}$ above the sea surface. Relative humidity, sea level barometric pressure and air temperature were measured at $3 \mathrm{~m}$ above the sea surface. Hourly data is only available for the instruments that were recovered from the ocean (August 2012 - July 2013). Daily averages of the data transmitted in near-real time from the mooring are available from the Pacific Marine Environmental Laboratory website (https://www.pmel.noaa.gov/tao/drupal/disdel/). We use the daily dataset from August 2012 - November 2014 for our heat budget analysis.

Figure 2 presents time series of a subset of observations from the mooring which will be described further in Section 4. There are some gaps in the subsurface temperature and salinity during the mooring operation period (Figure 2d-e). The longest gaps are during the second mooring deployment at depths of $80 \mathrm{~m}$ and $100 \mathrm{~m}$ for temperature and $80 \mathrm{~m}, 100$ $\mathrm{m}$, and $120 \mathrm{~m}$ for salinity. These gaps have been filled through vertical interpolation. There is no data at all depths for 14 days towards the end of the second deployment. However, these missing data do not affect conclusions of our analysis since mixed layer depth (MLD) is almost always shallower than the deeper gaps.

\subsection{Atmospheric reanalysis products}

Yu et al. (2007) and Kumar, Vialard, Lengaigne, Murty, and McPhaden (2012) have made a detailed comparison of different reanalysis products with in situ measurements for the Indian Ocean $\left(30^{\circ} \mathrm{N}-30^{\circ} \mathrm{S}\right)$ and global ocean $\left(30^{\circ} \mathrm{N}-30^{\circ} \mathrm{S}\right)$, respectively. They both conclude that OAFLux, ISCCP and ERA-I perform the best and NCEP products are least representative of the net heat flux variability. Kumar et al. (2012) introduces a new data product called TropFlux which is a combination of ERA-I atmospheric variables and OAFLux/ISCCP shortwave radiation fluxes. It is available globally for the latitudinal band $30^{\circ} \mathrm{N}-30^{\circ} \mathrm{S}$ on a spatial grid of $1^{\circ} \times 1^{\circ}$. TropFlux has been evaluated against mooring data and is a useful reanalysis product to study air-sea interactions and oceanic heat budgets in the tropics (Kumar et al., 2012). Here, for the spatial analysis, we used the monthly averages of TropFlux shortwave radiation and net heat flux during $2004-2015$.

The wind data from the mooring ends in December 2013. Therefore, we used TropFlux winds instead of mooring winds to extend the time series to the end of the deployment in November 2014. TropFlux wind agrees well with the mooring winds from August 2012 to 

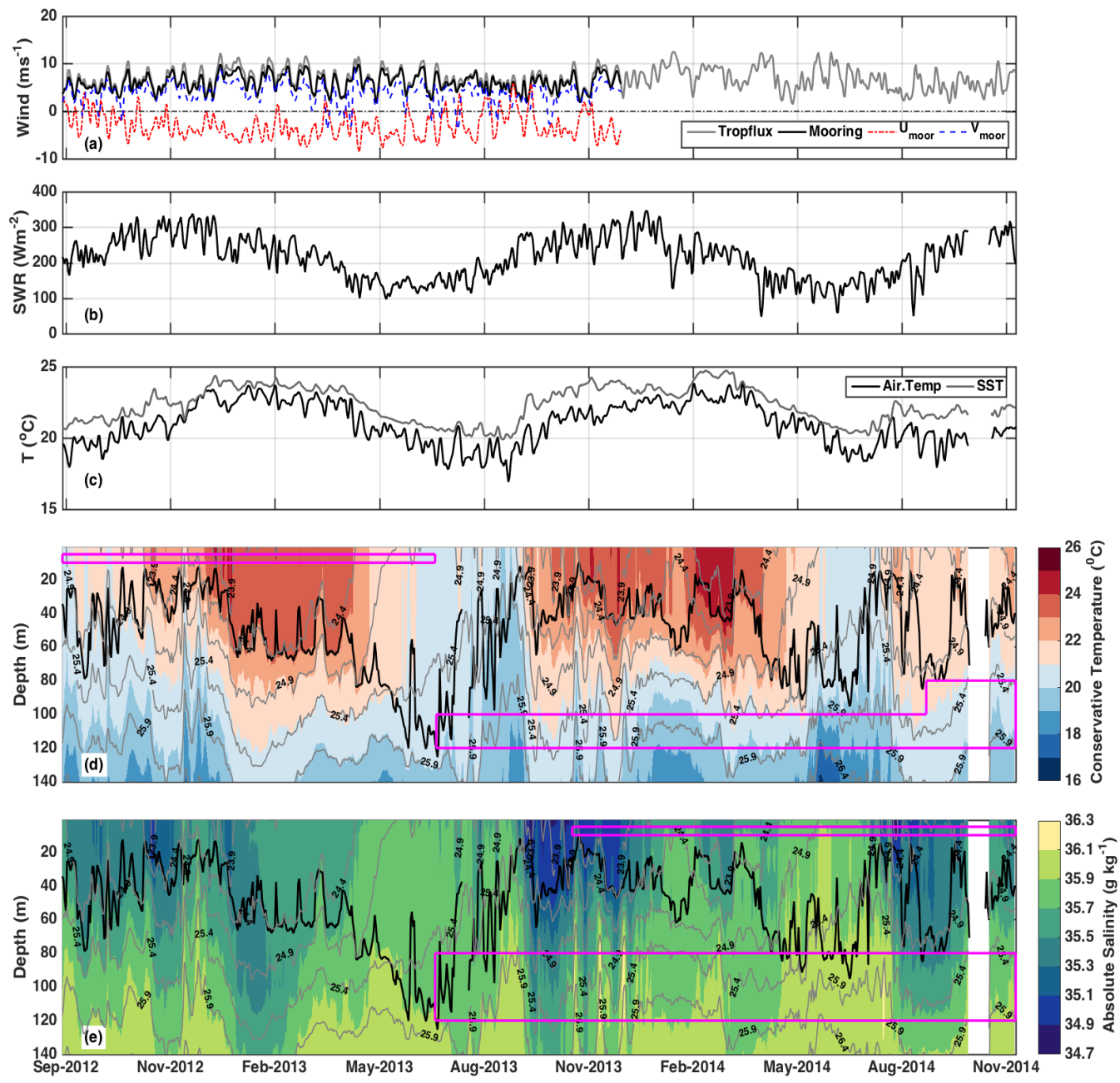

Figure 2. Daily time series of a) wind speed with zonal (red dashed line) and meridional (blue dashed line) components from mooring and wind speed from Tropflux b) shortwave radiation from mooring, c) air temperature and SST from mooring d) subsurface temperature and e) subsurface salinity overlaid with potential density contours (grey lines) and MLD (black line). The magenta boxes in (d) and (e) show the gaps that have been filled with linear interpolation in the vertical. All time series are filtered with a 1-2-1 running mean filter.

December 2013, with a correlation of 0.965 (Figure 2a). We also compared the mooring surface heat fluxes with those from different reanalysis products such as NCEP2, OA Flux, TropFlux and MERRA data. Among them, TropFlux (NCEP2) has the highest (lowest) correlation and smallest (largest) root mean square deviation (RMSD) with the mooring measurements. 


\subsection{Argo, Satellite and ocean reanalysis products}

We used the latest version of Roemmich-Gilson Argo data (Roemmich et al., 2009) for the 12-year analysis. The mapped fields of temperature and salinity on pressure surfaces derived from Argo profiles are available on a spatial grid of $1^{\circ} \times 1^{\circ}$. Monthly averages of Argo temperature and salinity profiles are available at the mooring location up to a depth of about $2000 \mathrm{~m}$ since 2004. By applying the same method as used for the observations (Section 3), we derived MLD from Argo data and also from Simple Ocean Data Assimilation ocean/sea ice reanalysis (SODA) data (Carton \& Giese, 2008). We compared the monthly averages of MLD from Argo and SODA with those from the mooring and found that they match well (supporting information Figure S2).

NOAA High Resolution SST data are used to provide information on horizontal gradients of SST. These daily data have a spatial resolution of $0.25^{\circ} \times 0.25^{\circ}$ and are provided by the NOAA/OAR/ESRL PSD, Boulder, Colorado, USA (http://www.esrl.noaa.gov/ psd/). Following Wang and McPhaden (1999) (hereafter WM99), we refer to this dataset as "Reynolds SST" throughout the paper. Reynolds SST matches well with the mooring SST with a correlation (RMSD) of $0.96^{\circ} \mathrm{C}\left(0.43^{\circ} \mathrm{C}\right)$ over the full 2-year record (supporting information Figure S3).

Since the ocean velocity measurements from the mooring were not reliable, we used Ocean Surface Current Analysis Real-time (OSCAR) current vectors to estimate horizontal advection. OSCAR velocities are provided on a $0.33^{\circ} \times 0.33^{\circ}$ grid with a 5 -day resolution from http://dx.doi.org/10.5067/OSCAR-03D01. The OSCAR climatology is found to capture the surface current variability in the tropical Indian Ocean reasonably well with a difference in magnitude of less than $0.2 \mathrm{~ms}^{-1}$ from drifter climatology (Sikhakolli et al., 2013). They also found that the OSCAR currents are in good agreement with currents measured by moorings. Here the OSCAR velocities were interpolated in time to match the daily mooring data, and interpolated spatially to the mooring location. Meridional velocity exhibits more variability than zonal velocity and the correlations between the few available mooring velocities and OSCAR are correspondingly higher for meridional velocity (0.82) than for zonal velocity (0.26). The RMSD between 5-day averages of available mooring currents and OSCAR is slightly higher for the meridional component $\left(0.16 \mathrm{~ms}^{-1}\right)$ than that of the zonal component $\left(0.15 \mathrm{~ms}^{-1}\right)$. This result gives us some confidence that the OSCAR 
velocities are realistic. We use the daily Reynolds SST and OSCAR velocities for the long term heat budget as well.

\section{Heat Budget}

To identify the processes contributing to the seasonal variability in mixed layer temperature, we analyze the surface layer heat balance at the mooring following WM99. The heat balance equation can be written as,

$$
Q_{t}=Q_{n e t}+Q_{u}+Q_{v}+Q_{r e s}
$$

$$
Q_{n e t}=Q_{S W}-Q_{L W}-Q_{L}-Q_{S}+Q_{p e n}
$$

$$
Q_{p e n}=-0.45 \times Q_{S W} \times e^{-\gamma H}
$$

$$
Q_{u}=-\rho C_{p} H u \frac{\partial T}{\partial x}
$$

$$
Q_{v}=-\rho C_{p} H v \frac{\partial T}{\partial y}
$$

$$
Q_{t}=\rho C_{p} H \frac{\partial T}{\partial t} .
$$

Here $H$ is the mixed layer depth, $\rho C_{p}$ is the volumetric heat capacity of seawater (equal to $4.038 \times 10^{6} \mathrm{JK}^{-1} \mathrm{~s}^{-3}$ ), $T$ is the average mixed layer temperature, and $u$ and $v$ are the eastward and northward currents in the mixed layer. $Q_{t}$ is the mixed layer temperature change rate, and $Q_{n e t}$ is the net surface heat flux (Equations 1 and 2) which is the sum of latent $\left(Q_{L}\right)$ and sensible $\left(Q_{S}\right)$ heat fluxes, net surface shortwave $\left(Q_{S W}\right)$ radiation obtained from the downward shortwave flux considering an albedo of $6 \%$ and net long wave $\left(Q_{L W}\right)$ radiation, and the penetrative $\left(Q_{p e n}\right)$ component of the shortwave radiation through the base of the mixed layer (Equations 2 and 3). Here positive heat flux terms represent gain to the ocean.

MLD is estimated as the depth at which density is $0.15 \mathrm{~kg} \mathrm{~m}^{-3}$ units denser than that at $5 \mathrm{~m}$ depth (Foltz, Vialard, Kumar, \& McPhaden, 2010). Since the mixed layer temperature and SST are similar (supporting information Figure S3) we use mooring SST for the 2 year analysis and Reynolds SST for the 12 year analysis to estimate the heat storage.

$Q_{p e n}$ is estimated following Morel and Antoine (1994) solar irradiance parameterization as described in Sweeney et al. (2005) using a chlorophyll-a concentration of $0.1 \mathrm{mg} \mathrm{m}^{-3}$. The outgoing $Q_{L W}$ is calculated by long wave radiation emission at the sea surface. $Q_{L}$ and 
$Q_{S}$ are estimated using the Coupled Ocean-Atmosphere Response Experiment (COARE) bulk flux algorithm (Fairall, Bradley, Rogers, Edson, \& Young, 1996),

$$
Q_{L}=\rho_{a} L_{e} C_{e} S\left(q_{s}-q\right)
$$

$$
Q_{S}=\rho_{a} C_{p a} C_{h} S\left(T_{S}-\theta\right),
$$

where $\rho_{a}$ is the air density, $L_{e}$ is the average latent heat of vaporisation and $C_{p a}$ is the specific heat capacity of air. $C_{e}$ (Dalton number) and $C_{h}$ (Stanton number) are the transfer coefficients for $Q_{L}$ and $Q_{S}$ respectively. $q$ is the water vapour mixing ratio, $q_{s}$ is the interfacial value of the water vapour mixing ratio, $T_{s}$ is the sea surface interface temperature which we consider as the SST and $\theta$ is the potential temperature of the air above.

For advection, the temperature gradients were calculated using Reynolds SST (Figure 1c-d) around the mooring location. We use upstream differencing following Bond and McPhaden (1995) to estimate the horizontal advection. When the flow is northward (eastward), the gradient south (west) of the mooring is estimated and when the flow is southward (westward), the gradient north (east) of the mooring is considered. We choose $1^{\circ}$ spacing to estimate the meridional temperature gradient, and $2^{\circ}$ spacing for the zonal temperature gradient, recognising the stronger meridional gradients in this region. We also tried different resolutions $\left(0.5^{\circ}, 1^{\circ}, 1.5^{\circ}, 2^{\circ}\right)$ and found that it does not affect the conclusions of the study.

The vertical turbulent heat flux into the mixed layer is estimated as a residual $\left(Q_{\text {res }}\right)$ between $Q_{n e t}$, advection and heat storage (WM99). It combines the effects of vertical entrainment and vertical heat diffusivity. It also encompasses neglected physical processes and errors in the estimates of the other terms in the heat budget.

We averaged the daily heat budget terms to monthly averages and the seasonal cycles were estimated from the monthly averages. In order to be consistent with the mooring analysis, we estimated the fluxes for the spatial analysis by using each monthly average of MLD for every day of each month to get daily values. Following Foltz and McPhaden (2008), the standard error in the monthly heat budget was estimated using the daily mooring data. The effective degrees of freedom corresponds to a decorrelation timescale of $3-4$ days. The standard error for the spatial analysis is also calculated in the same way but calculating the standard error from the monthly data. Also, the mean seasonal cycles are smoothed with a 1-2-1 monthly filter to eliminate the intraseasonal noise that tends to obscure the lower frequency component of the seasonal cycle that we are most interested in. 


\section{Mixed layer heat balance from the RAMA mooring}

\subsection{Observed variability}

The southeasterly trade winds dominate the wind record with strong daily fluctuations (Figure 2a). The $Q_{S W}$ has strong seasonal fluctuations with comparatively weaker interannual variability (Figure $2 \mathrm{~b}$ ). SST is always higher than the air temperature for all seasons and synoptic events (Figure 2c), with small daily fluctuations. The seasonal cycles of both SST and air temperature follow that of $Q_{S W}$. The subsurface temperature, salinity and MLD have a strong seasonal cycle (Figure $2 \mathrm{~d}$ and e). Note that the density contours are following temperature contours well suggesting that the salinity is of secondary importance to density variations in this region. The upper ocean is warm and fresh during austral summer with a shallow mixed layer. During austral winter, the upper ocean is colder and more saline with a deeper mixed layer.

\subsection{Seasonal cycle}

The mooring data at $25^{\circ} \mathrm{S}, 100^{\circ} \mathrm{E}$ show strong seasonal variations (Figure 3). The dominant wind direction is from the southeast throughout the year. The wind stress has a weak 2 cycle per year variation with higher values during austral summer and winter (Figure 3a). SST is higher during austral summer with a peak value $\left(\sim 24^{\circ} \mathrm{C}\right)$ in March and decreases to a minimum in July $\left(\sim 20.5^{\circ} \mathrm{C}\right)$. Sea surface salinity (SSS) follows an opposite variation compared to SST (Figure 3b and c) with the highest surface salinity observed in June (35.6 psu) and the lowest in October ( $\sim 35 \mathrm{psu})$. The mixed layer is deepest during June - July $(\sim 80 \mathrm{~m})$, when the mixed layer is colder and saltier, and shallowest in December when the mixed layer is warmer and fresher (Figure 3d). Ekman pumping $w_{E}$ (Figure 3e), computed from the curl of the wind stress $\left(w_{E}=\frac{1}{\rho f}\left[\frac{\partial \tau_{y}}{\partial x}-\frac{\partial \tau_{x}}{\partial y}\right]\right)$ is negative on average (downwelling) as would be expected since the mooring is located in a region of net subduction (Karstensen \& Quadfasel, 2002; Zhang \& Talley, 1998). There is also a strong seasonal cycle in $w_{E}$, with largest values in austral winter. These Ekman pumping velocities appear to influence the MLD (Figure 3d) which is deepest when downwelling is strongest. The surface heat fluxes have weak seasonality except the $Q_{S W}$ term (Figure 3f) which varies from $\sim 150$ $\mathrm{Wm}^{-2}$ during austral winter up to $\sim 290 \mathrm{Wm}^{-2}$ during summer. Winter time $Q_{S W}$ is similar to year round $Q_{L}$ values. The contribution of $Q_{L W}$ and $Q_{S}$ to the $Q_{n e t}$ are small compared to $Q_{L}$. The annual mean of $Q_{L W}$ is $\sim 60 \mathrm{Wm}^{-2}$ with a weak maximum in austral 

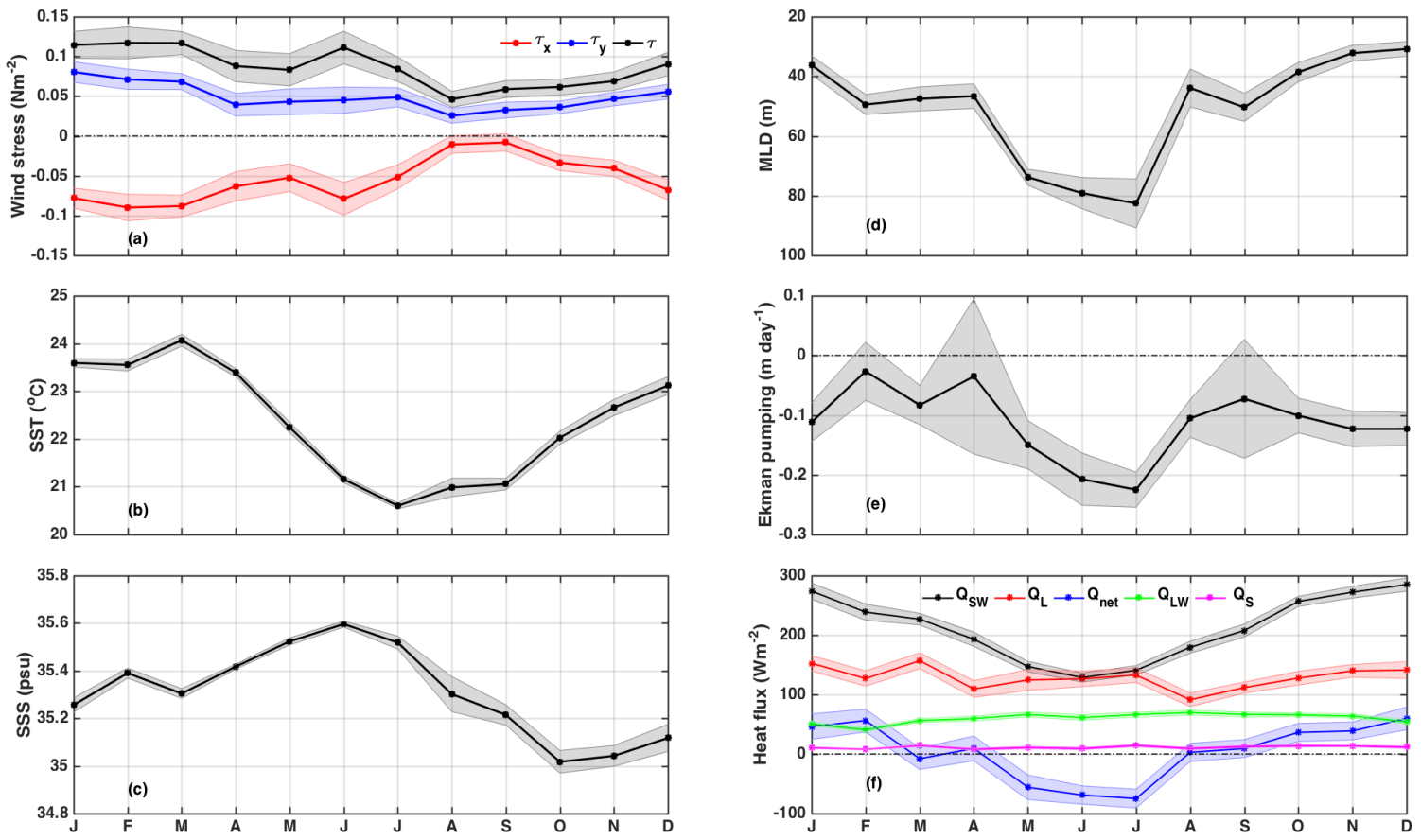

Figure 3. Monthly mean seasonal cycles of a) Wind stress and its components, b) SST c) SSS, d) MLD, e) Ekman pumping, and f) surface heat fluxes $\left(Q_{S W}, Q_{L}, Q_{n e t}, Q_{L W}, Q_{S}\right)$. Shading shows one standard error.

summer-spring. During austral winter, the ocean experiences a net heat loss at the surface due to reduced incoming $Q_{S W}$. In austral summer, the increased incoming solar radiation results in a net heat gain at the surface.

\subsection{Heat budget at $25^{\circ} \mathrm{S}, 100^{\circ} \mathrm{E}$}

The heat budget at the $25^{\circ} \mathrm{S}, 100^{\circ} \mathrm{E}$ RAMA mooring site is estimated as described in Section 3. Daily heat budget terms overlaid with 30-day smoothed values are presented in Figure 4. $Q_{\text {pen }}$ is stronger during austral summer when the mixed layer is shallow (Figure 4b). The zonal advection is comparatively small during most of the mooring record whereas the meridional advection fluctuates more (Figure 4d and e). The daily fluctuations of all terms are substantial except for $Q_{p e n}$ (Table 1).

The daily heat budget terms are averaged to produce the mean seasonal cycle of the heat budget at the mooring location (Figure 5$)$. The ocean gains heat $\left(\sim 50 \mathrm{Wm}^{-2}\right)$ during 

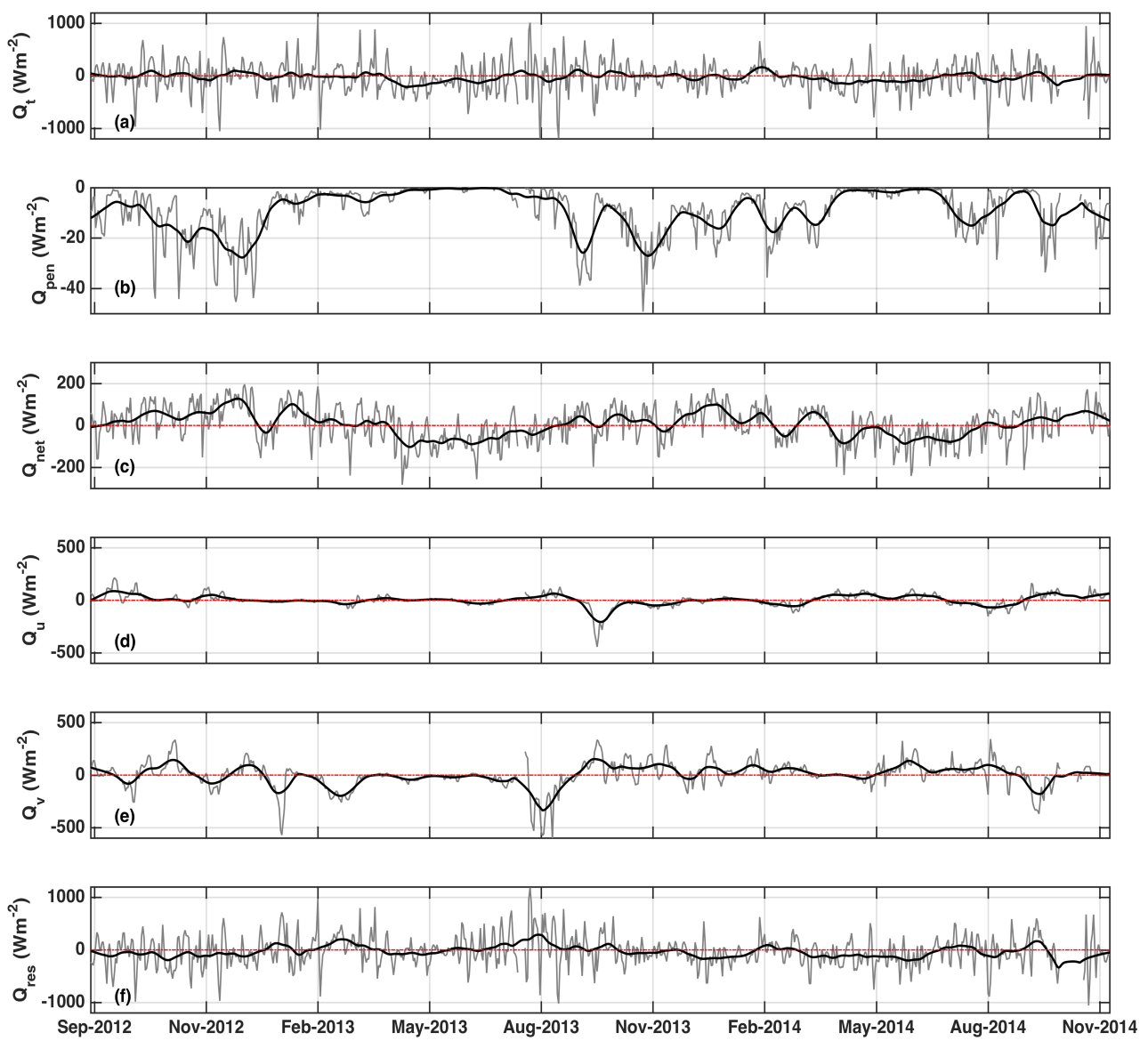

Figure 4. Daily estimates (grey line) of a) $Q_{t}$, b) $Q_{p e n}$ c) $Q_{n e t}$, d) $Q_{u}$ e) $Q_{v}$ and f) $Q_{r e s}$ from the RAMA mooring at $25^{\circ} \mathrm{S}, 100^{\circ} \mathrm{E}$. The black line is the 30 -day smoothed time series. The zero line is highlighted in red.

austral summer and loses heat $\left(\sim 60 \mathrm{Wm}^{-2}\right)$ during austral winter through the air-sea interface $\left(Q_{n e t}\right.$, Figure 5, blue line). The $Q_{t}$ heat storage term (Figure 5, red line) shows the cooling of the mixed layer during austral winter and warming during austral summer. $Q_{v}$ (magenta line, Figure 5) has a 2 cycle per year variation with warming during austral winter and summer and cooling during austral spring and autumn. $Q_{u}$ acts to cool the mixed layer in late summer (January - March) and then warms the mixed layer for the rest of the year. The combined effect of $Q_{u}$ and $Q_{v}$ is warming during early winter and early summer, significant cooling only in autumn, and little effect on the heat budget at 
Table 1. The mean and standard deviation $\left(\mathrm{Wm}^{-2}\right)$ of heat fluxes from the mooring for daily and monthly time series. The monthly standard deviation contains both seasonal and interannual variability. This includes influences from the La Nina conditions in early 2012 and the positive Indian Ocean Dipole event in 2012.

\begin{tabular}{lccc}
\hline Heat flux & \multicolumn{2}{c}{ Daily } & Monthly \\
\hline & Mean & Std.Dev. & Std.Dev. \\
\hline$Q_{t}$ & -20.25 & 313.68 & 68.92 \\
$Q_{p e n}$ & -7.39 & 8.34 & 5.7 \\
$Q_{n e t}$ & 6.19 & 85.2 & 49.55 \\
$Q_{u}$ & 0.62 & 60.74 & 46.67 \\
$Q_{v}$ & 3.53 & 128.61 & 82.71 \\
$Q_{r e s}$ & -30.86 & 314.35 & 99.41 \\
\hline
\end{tabular}

other times. $Q_{\text {res }}$ is the main driver of cooling throughout the year, reaching a peak of 80 $\mathrm{Wm}^{-2}$ in May and December and reducing to near zero in late summer and late winter. Therefore, $Q_{r e s}$ is the primary cooling term during austral autumn - winter. $Q_{n e t}$ is the second largest term. The warming during austral spring - summer is mainly driven by $Q_{n e t}$ and secondarily by $Q_{v}$. The total advection is a non-negligible source of warming during the austral winter, greatly offsetting $Q_{n e t}$.

The residual $Q_{\text {res }}$ from the mooring analysis has a similar seasonal cycle to the residual in the eddy resolving model of Feng et al. (2008). The model residual is negative most of the year except during austral winter when the mixed layer depth is deeper. The model residual includes vertical mixing and penetrative solar radiation as well as unresolved processes. Possible reasons for the seasonality of $Q_{\text {res }}$ are explored in Section 4.5.

\subsection{Horizontal advection}

We consider the two cycle per year of warming due to horizontal advection in light of the strong eddy field in this region (Fang \& Morrow, 2003; Feng, Majewski, Fandry, \& Waite, 2007; Jia et al., 2011; Morrow \& Birol, 1998). We separated the advection terms into low-frequency (mean) and high-frequency (eddy) components to investigate the impact 
of eddies on the advection terms. For example, the advection term can be written as $\overline{Q_{u}}=-\rho \times C_{p} \times\left(\bar{u} \bar{H} \overline{\frac{\partial T}{\partial x}}+\overline{u^{\prime} H^{\prime} \frac{\partial T^{\prime}}{\partial x}}+\bar{H} \overline{u^{\prime} \frac{\partial T^{\prime}}{\partial x}}+\bar{u} \overline{H^{\prime} \frac{\partial T^{\prime}}{\partial x}}+\overline{\frac{\partial T}{\partial x}} \overline{u^{\prime} H^{\prime}}\right)$, where overbar denotes monthly means and primes denote deviations from the monthly means (Zhang \& McPhaden, 2010). Note that the velocities used are from OSCAR 5-day data and so do not resolve daily fluctuations. The decomposition shows that the eddy component dominates the mean component for both zonal and meridional advection (Figure 6), suggests that the highfrequency components play an important role in the advection terms.

The unusually strong EKE in this region with a maximum close to the eastern boundary, has been investigated in many studies to identify the source of the variability. Several possibilities have been suggested: Rossby waves with annual and semi-annual frequencies (Morrow \& Birol, 1998); baroclinic instability of the LC leading to generation of the mesoscale eddies that propagate westward far into the Indian Ocean (Fang \& Morrow, 2003; Feng et al., 2007; Feng, Meyers, Pearce, \& Wijffels, 2003; Morrow et al., 2003); baroclinic instability of the eastward flowing SICC (Jia et al., 2011) that generates eddies away from the coast. The Rossby waves propagating from the LC region are associated with propagating anomalies in both SST and SSH (Morrow \& Birol, 1998) with peak anomalies in May and November. Morrow and Birol (1998) found SST anomalies of $\pm 1^{\circ} \mathrm{C}$ propagating through the basin with a lifetime of more than six months (their Figure 6). The LC transport, and the associated EKE close to the Australian coast, is strongest during austral winter and weaker during austral summer (Fang \& Morrow, 2003; Feng et al., 2007, 2003; Godfrey \& Ridgway, 1985). This is opposite in phase to peaks in EKE reported by Jia et al. (2011) for the central Indian Ocean $\left(15-30^{\circ} \mathrm{S}, 60-110^{\circ} \mathrm{E}\right)$ where they found highest EKE in austral summer and lowest in austral winter. This suggests a role for propagation of anomalies from the coast. Indeed, Jia et al. (2011) found that the strongest EKE signals occur east of $90^{\circ} \mathrm{E}$ with decaying amplitudes towards the west.

We estimate the time taken for eddies generated in the LC to propagate westward to the mooring location using SSH variability. The slope of the time-longitude diagram of SSH (Figure 7, left panel) indicates a speed of propagation of $6.3 \mathrm{~ms}^{-1}$. This is slightly larger than the propagation speed of nondispersive baroclinic Rossby waves at $25^{\circ} \mathrm{S}$ (Chelton, Schlax, Samelson, \& de Szoeke, 2007). Eddies travelling due westward therefore take about 6 months to reach the mooring location from the coast of western Australia, arriving in November/December at the time of the summer peak in the heat advection (Figure 5). 
The peak SSH variability at the mooring location during the deployment period occurs from September - February (Figure 7), which could include inter-annual as well as seasonal variability. The summer peak in heat advection may also have a contribution from the local generation of eddies (Jia et al., 2011). The zonal transport of the central and southern branches of the SICC (north and south of the mooring, respectively) reaches a maximum in September - October (Menezes et al., 2014). This coincides with the peak in vertical shear between the SICC and subsurface westward flow, and precedes the summer peak in EKE by $2-4$ months (Jia et al., 2011). Thus, the relationship between the timing of the winter peak in meridional advection and variability in the SICC is tantalizing and warrants further investigation.

Mechanisms driving the winter peak in heat advection at the mooring could include propagation of signals from the coast such as the annual and semi-annual Rossby waves identified by Morrow and Birol (1998), LC eddies, and local instabilities of the SICC near the mooring location (Jia et al., 2011). We also note that some of the anomalies in Figure 7 do not seem to originate at the coast. Eddies in this region are known to propagate meridionally as well as zonally: warm core eddies tend to move equatorward and cold core eddies poleward (Morrow et al., 2004). Therefore, eddies may cut across our $25^{\circ} \mathrm{S}$ line, and appear to originate away from the coast when their origin at the coast is clear in SSH animations.

\subsection{Residual}

The residual $\left(Q_{r e s}\right)$ represents the effect of vertical processes such as turbulent heat diffusion, vertical advection, entrainment that cools the mixed layer, detrainment that warms the mixed layer when it shoals (Cronin, Pelland, Emerson, \& Crawford, 2015; Niiler, 1977), neglected physical processes, and the errors in estimating other terms in the heat budget. The neglected physical processes include lateral induction and the effects of vertical movements of the thermocline due to adiabatic motions (Stevenson \& Niiler, 1983). In principle, the detrainment is identically zero if the mixed layer is perfectly isothermal (Cronin et al., 2015) and it usually does not warm the mixed layer except if slightly colder water sheds off during mixed layer shoaling (Kim, Lee, \& Fukumori, 2007). The effect of large-scale entrainment mixing in cooling and deepening the mixed layer is usually larger than the detrainment warming (Cronin et al., 2015). Therefore negative residuals are more likely 

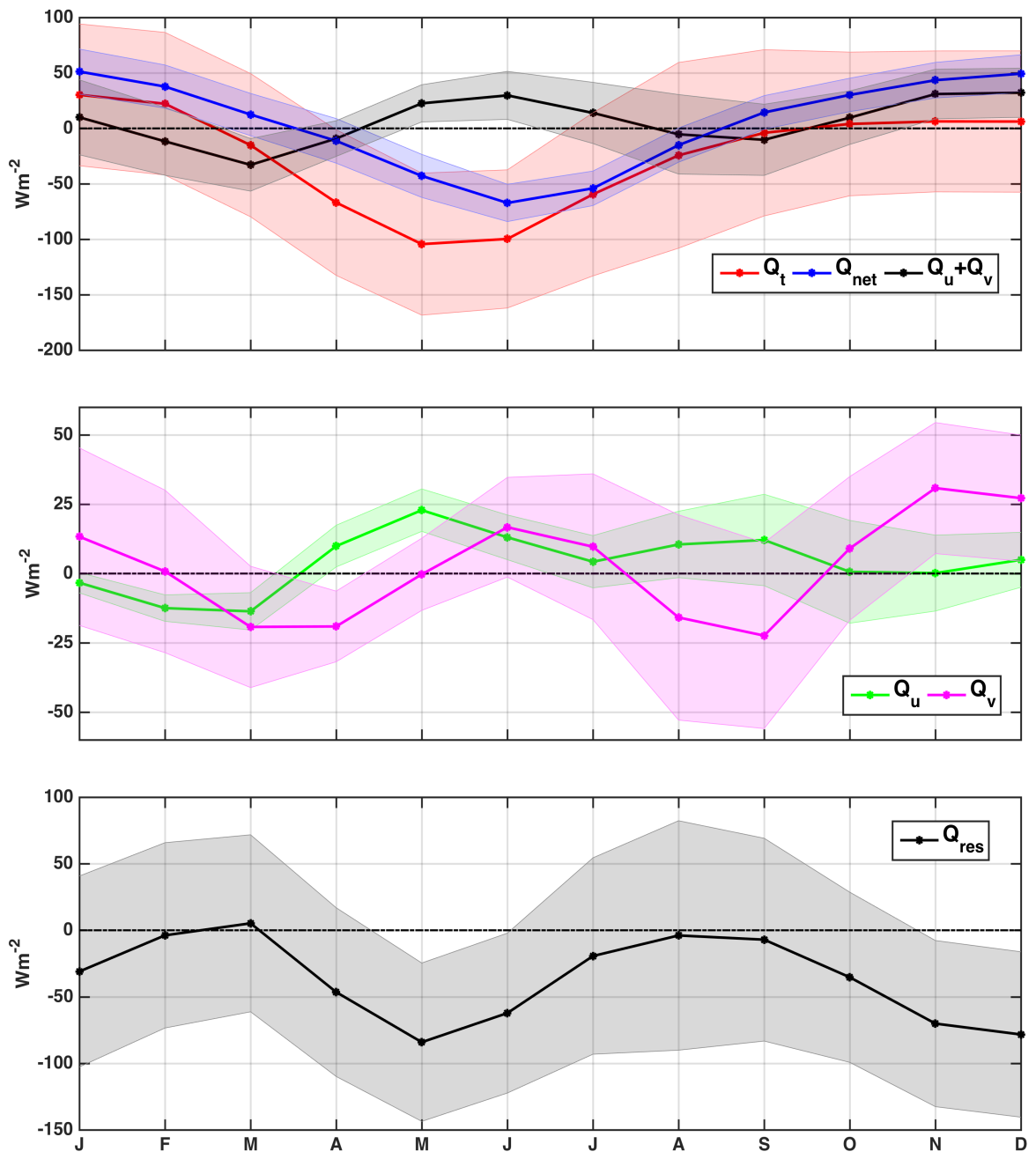

Figure 5. Seasonal cycle of $Q_{t}, Q_{n e t}, Q_{u}, Q_{v}$ and $Q_{r e s}$ from the RAMA mooring at $25^{\circ} \mathrm{S}, 100^{\circ} \mathrm{E}$. The standard error for each term is shown in shading. All seasonal cycles are filtered by a 1-2-1 running mean filter.

to represent a physically meaningful process that cools the mixed layer. Positive residuals could be due to sampling and computational errors or due to some processes that we have neglected.

According to the turbulent energy balance of the surface mixed layer, turbulent entrainment can be driven by wind and buoyancy flux. The resulting entrainment velocity $w_{e}$ 

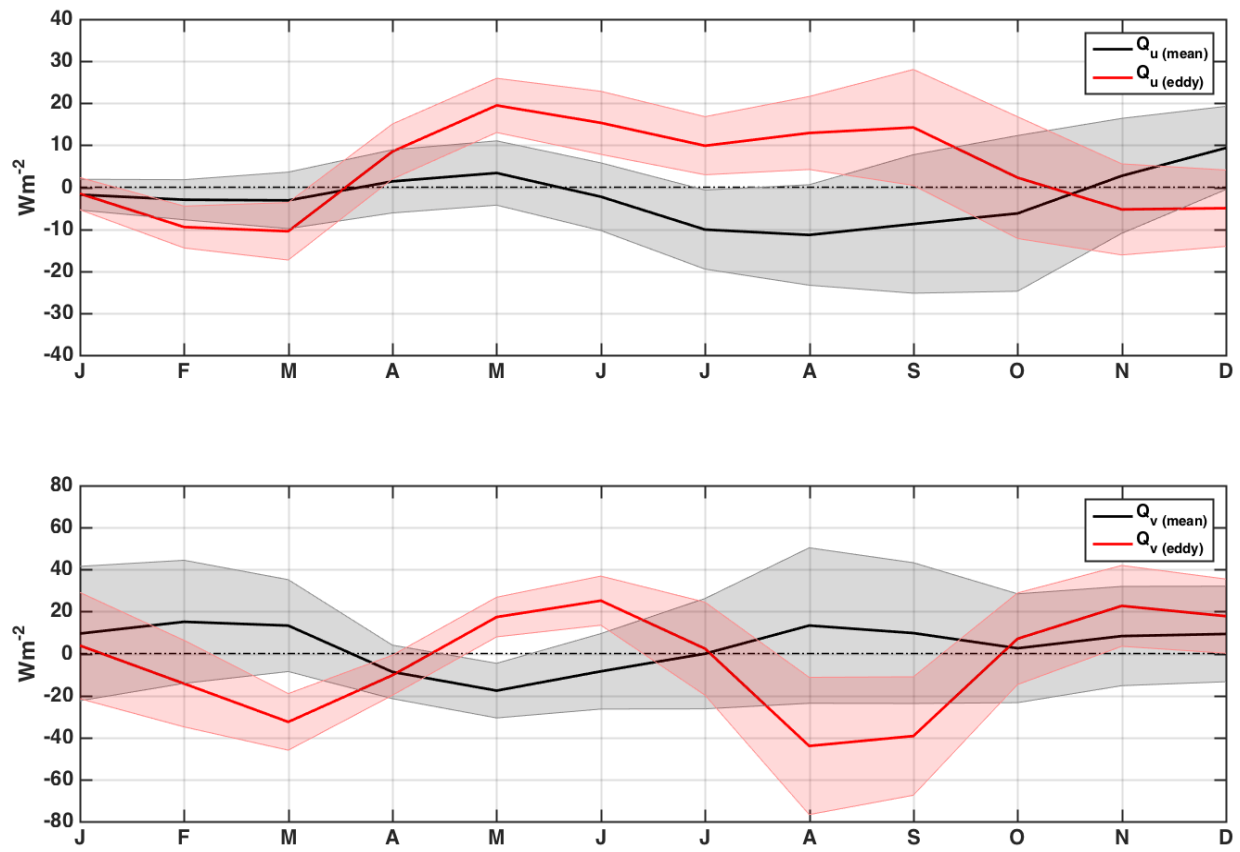

Figure 6. Seasonal cycle of mean and eddy parts of zonal advection (upper panel) and that of meridional advection (bottom panel). Note the different scales in the two panels.

can be written as (Niiler, 1977),

$$
w_{e}=\frac{2 m u_{*}^{3}+\frac{H}{2}[(1+n) B-(1-n)|B|]+\left(H-\frac{2}{\gamma}\right) J}{c_{i}^{2}-s|\Delta v|^{2}} .
$$

Here we follow the notations of Foltz et al. (2010) where $m, n$, and $s$ are proportionality constants, $H$ is the mixed layer depth, $1 / \gamma$ is the shortwave extinction depth, $J$ is proportional to the surface shortwave radiation, $c_{i}^{2}$ is proportional to the buoyancy difference across the mixed layer base, and $\Delta v$ is the difference of averaged mixed layer horizontal velocity from that at the mixed layer base. Also $u_{*}$ is the friction velocity (Foltz et al., 2010; Niiler, 1977) where

$$
u_{*}=\sqrt{\tau / \rho} .
$$

Here $\tau$ is the wind stress and $\rho$ is the ocean density. The buoyancy flux $B$ can be written as (Foltz et al., 2010)

$$
B=\alpha c_{p}^{-1} Q_{n e t}+\beta \rho S(P-E),
$$



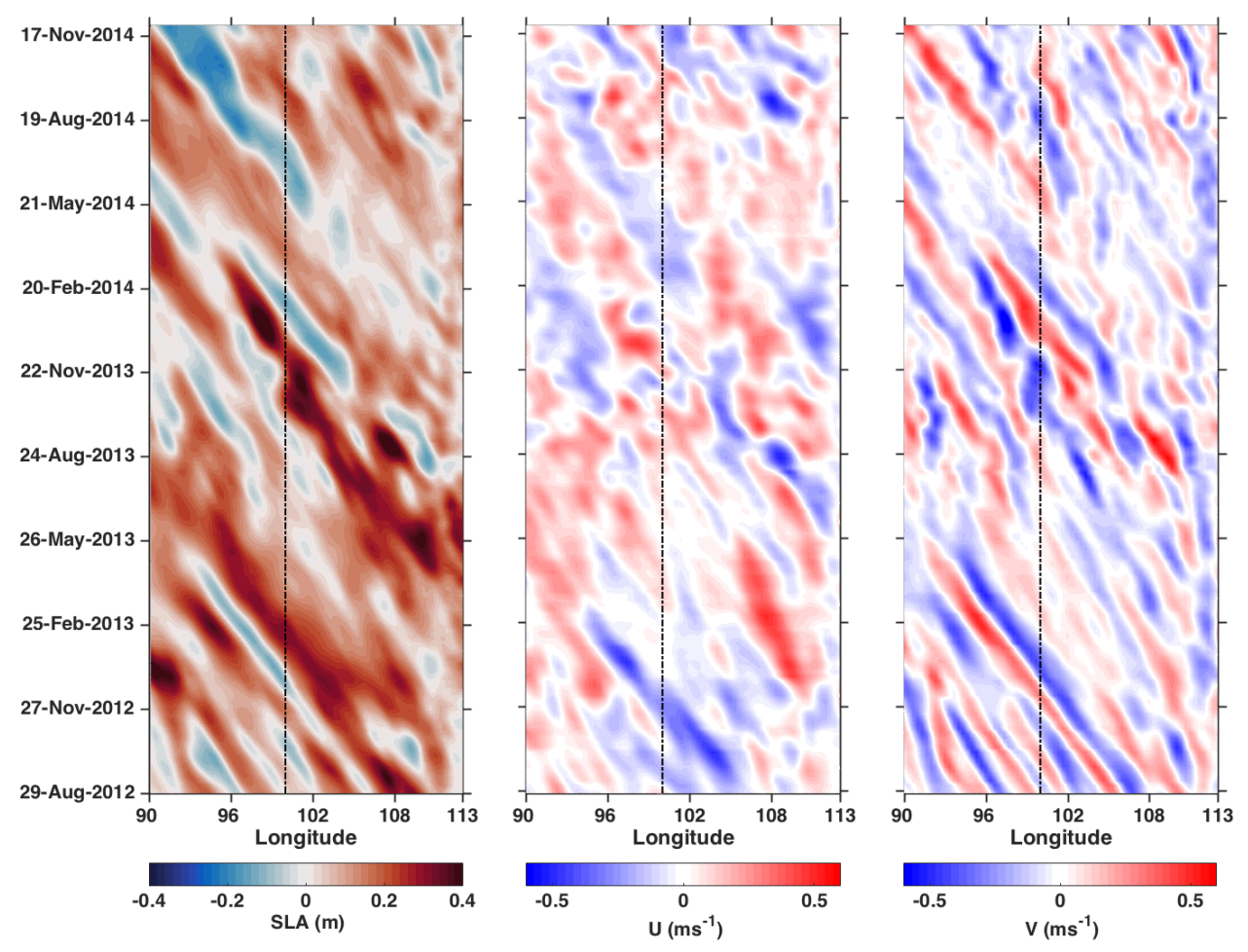

Figure 7. Time-longitude diagram of sea level anomaly (left panel) from AVISO, OSCAR zonal velocity (middle panel) and meridional velocity (right panel) during the mooring period at $25^{\circ} \mathrm{S}$. The sea level anomalies propagate westward with a speed of $\sim 6.3 \mathrm{~cm} \mathrm{~s}^{-1}$.

where $\alpha$ is the coefficient of thermal expansion and $\beta$ is the saline contraction coefficient. Here, $S$ is the sea surface salinity, $P$ is the rate of precipitation and $E$ is evaporation.

$Q_{r e s}$ is weak during the beginning of austral spring and autumn compared to austral summer and winter (Figure 8a). The seasonal cycle of $Q_{\text {res }}$ can be partially explained by that of $u_{*}^{3}$ and buoyancy flux (Figure $8 \mathrm{~b}$ and c). During austral summer, the wind stirring drives entrainment when the mixed layer is shallow and there is gain of buoyancy. During austral winter, the wind stirring, augmented by buoyancy loss from the surface, drives the entrainment. The two sources of turbulence during austral winter can result in deeper mixed layers than in austral summer. Since the behaviour of friction velocity and buoyancy flux seems to partially explain the seasonal cycle of $Q_{r e s}$ only during austral summer and winter, the residual flux may not be entirely driven by buoyancy flux and wind stirring. 
Assuming $m=0.4$ and $n=0.6$ as in Foltz et al. (2010), we estimated the entrainment velocity using equation 9 . We neglected the $\Delta v$ term since we do not have velocity measurements from the mooring.

We also estimated entrainment velocity from the mixed layer depth variation as

$$
w_{e}=H\left(\frac{d h}{d t}+w(-h)\right)
$$

where $H=0$ for $\frac{\partial h}{\partial t} \leq 0$ and $H=1$ for $\frac{\partial h}{\partial t}>0$. Here $w(-h)$ is the vertical velocity at the base of the mixed layer, which is the time rate of change of the depth of an isotherm not far below the mixed layer. The $w_{e}$ from this method is sensitive to the choice of the MLD and isotherm.

The entrainment heat flux due to $w_{e}$ from both methods can then be written as $Q_{e}=$ $\rho c_{p} \Delta T w_{e}$ where $\Delta T$ is the difference between average mixed layer temperature and the temperature at the base of the mixed layer.

The magnitude of the entrainment fluxes from equation $(9)\left(Q_{\operatorname{ent}(N)}\right)$ and equation (12) $\left(Q_{\text {ent }(-h)}\right)$ is shown in Figure 9a. The entrainment cooling from $Q_{e n t(N)}$ and $Q_{\text {ent }(-h)}$ is comparatively higher during austral summer than austral winter in agreement with the residual from the heat budget. During austral winter, the cooling from $Q_{\text {ent }(N)}$ reaches a minimum whereas the heat budget residual is much higher. During austral spring and autumn, the cooling due to entrainment flux from both methods is stronger than the residual which is assumed to be due to vertical processes. In an attempt to better resolve the residual, we also estimated a new residual $\left(Q_{r e s(N)}\right.$ and $\left.Q_{r e s(-h)}\right)$ by explicitly including the entrainment fluxes in the heat budget. The new residuals are reduced during austral summer especially during November - December, when the entrainment cooling from both methods is high. During austral winter, explicitly accounting for $Q_{e n t(N)}$ does not reduce the residual much whereas explicitly accounting for $Q_{\text {ent }(-h)}$ does (Figure 9b). However, $Q_{\text {ent }(-h)}$ is positive throughout the year except during the key cooling phase of the cycle, April - June. This could be due to a number of reasons such as 1) the noise in the heat budget calculation is underestimated, 2) the entrainment flux estimates do not fully capture the vertical processes, 3) the horizontal eddy processes are not fully captured with OSCAR velocities, 4) neglecting the detrainment, which is important when buoyancy fluxes re-stratify the mixed layer or 5) some combination of the above. 

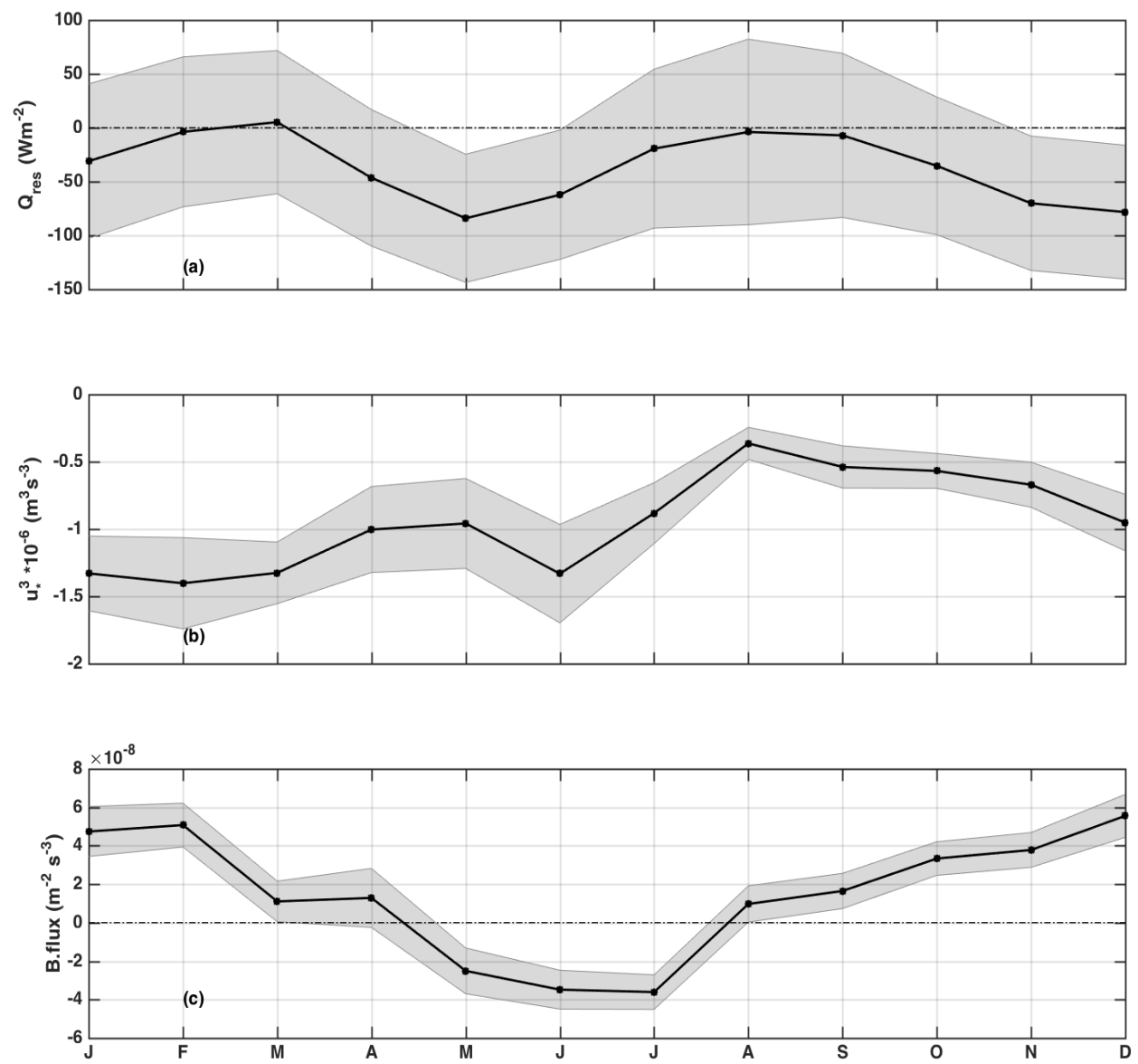

Figure 8. Seasonal cycle of a) $Q_{r e s}$, b) cube of friction velocity and c) buoyancy flux. Shading in all plots are the corresponding standard errors.

\section{Mixed layer heat balance from TropFlux, Argo and OSCAR}

The two year mooring record is relatively short to accurately quantify a seasonal heat balance. In order to support the mooring heat budget, we analyzed the upper ocean heat balance using daily reanalysis products and monthly Argo mixed layer depth data for the period $2004-2015$ over a larger region around the mooring. The mooring is located at the northern edge of the subduction zone with deeper mixed layers toward the south (Figure $10)$. 

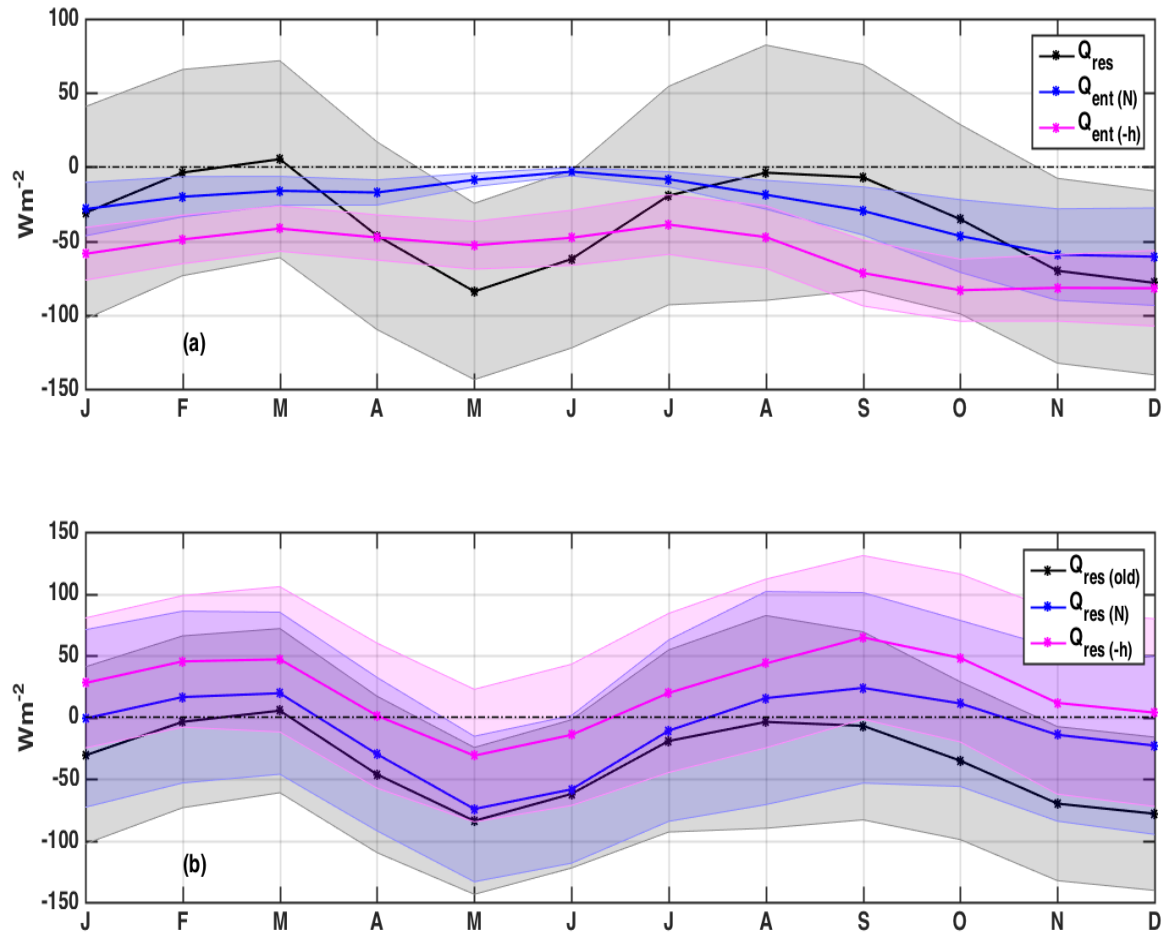

Figure 9. Seasonal cycle of a) $Q_{\text {res }}$ (black), entrainment using equation 9 (blue) and equation 12 (magenta) and b) $Q_{\text {res }}$ (black) as originally calculated but with entrainment removed, where entrainment is calculated using equation 9 (blue) and equation 12 (magenta).

\subsection{TropFlux adjustment}

For the spatial analysis, we used the monthly averages of TropFlux shortwave radiation and net heat flux during 2004 - 2015 (Figure 11). When we compared the monthly averages of mooring fluxes with those from TropFlux, we found that the TropFlux shortwave radiation and net heat flux are underestimated during austral summer and winter with a difference in magnitude of $\sim 50 \mathrm{Wm}^{-2}$ during austral winter (Figure 11). This difference could be due to the fact that TropFlux was corrected using mooring data until only 2009 (Kumar et al., 2012) when the subtropical Indian Ocean mooring was not yet deployed. Therefore we used a linear regression to correct the TropFlux shortwave radiation and net heat flux against the mooring measurements (Figure 12). The mooring shortwave radiation and net heat flux are highly correlated with that of TropFlux (0.93 and 0.77 respectively) suggesting that the two data sets are coherent with one another. Using the empirical relations from the regression, 

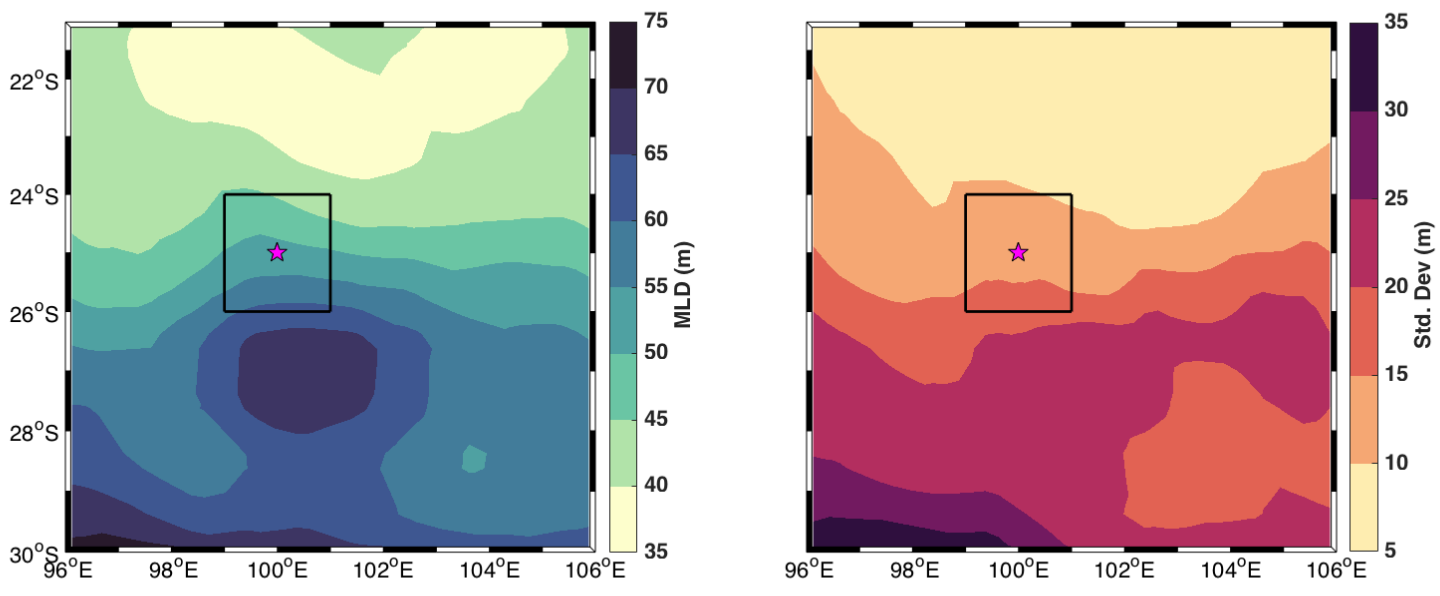

Figure 10. a) 12-year average and b) monthly standard deviation of mixed layer depth (m) from Argo data. The box encloses the region over which the seasonality of the heat budget terms are analyzed. The star represents the location of the mooring.

we adjusted the TropFlux shortwave radiation and net heat flux for the full 12-year period and used the adjusted TropFlux data for the spatial analysis around the mooring site.

\subsection{Spatial and temporal variability}

The mean of mixed layer heat storage during 2004 - 2015 shows a stronger cooling trend to the northwest of the mooring (Figure 13a). This suggests that the loss of heat from the mixed layer during austral winter is not balanced by the heat gain during austral summer. The spatial distribution of $Q_{p e n}$ is in accordance with that of the MLD with less loss towards the south where the mixed layer is deep (Figure 13c-d). The mean of $Q_{n e t}$ is weakly positive with less spatial variability throughout the region (Figure 13e-f) suggesting that the ocean gains heat through the air-sea interface in this region.

The spatial variability of advection terms is larger than that of the surface heat fluxes (Figure 14e-h) which could be related to the large eddy variability in this region (Section 

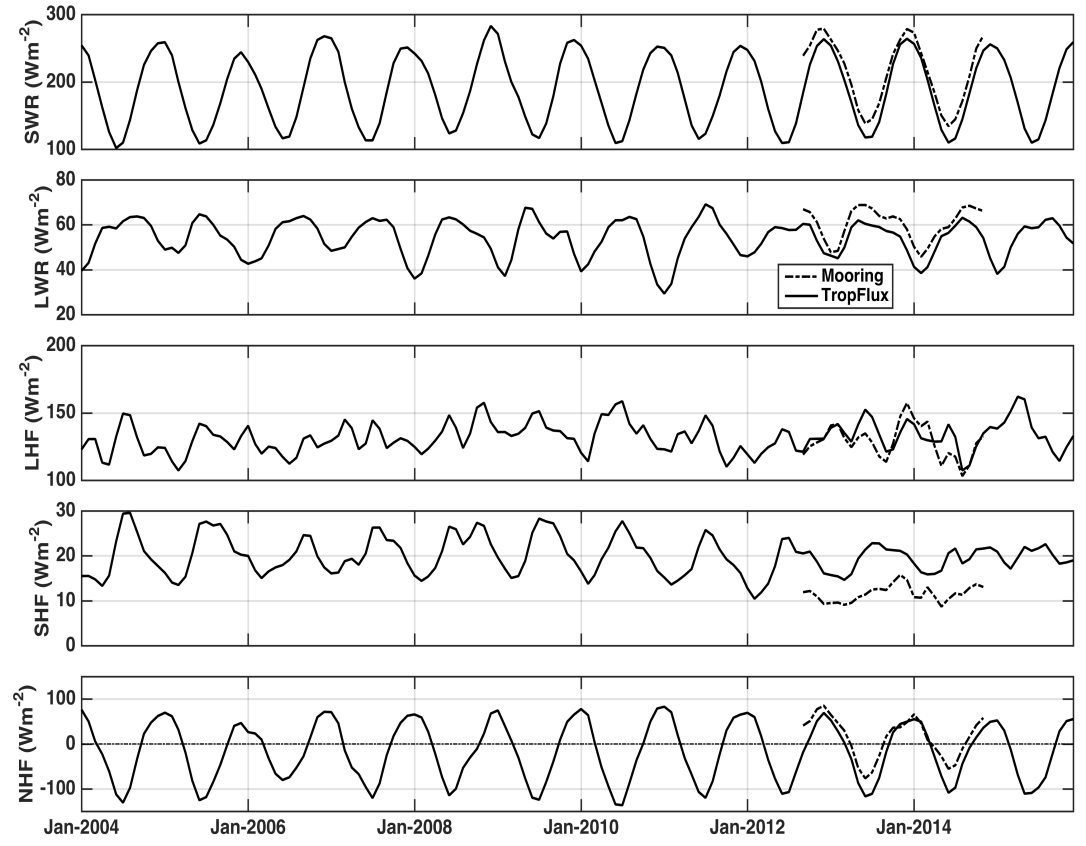

Figure 11. Monthly averages of surface fluxes from TropFlux (bold) and mooring (dashed) at the mooring location.

4.4). We separated the mean and eddy terms for the long term analysis at the mooring location as described in Section 4.4 and found that the eddy fluxes are large and dominate the zonal component of the total flux (not shown). The meridional eddy fluxes are of similar magnitude to the mean fluxes and have a 2 cycle per year variability as seen in the mooring analysis. On average, $Q_{u}$ cools the mixed layer around the mooring whereas $Q_{v}$ warms it. The warming from $Q_{v}$ is stronger towards the south of the mooring. The spatial variability of $Q_{r e s}$ is broadly similar to that of the advection which is highly variable compared to the surface heat fluxes. There are areas with evident positive residuals where possible sampling and computational errors may be prominent enough to overwhelm any signature of vertical mixing. 

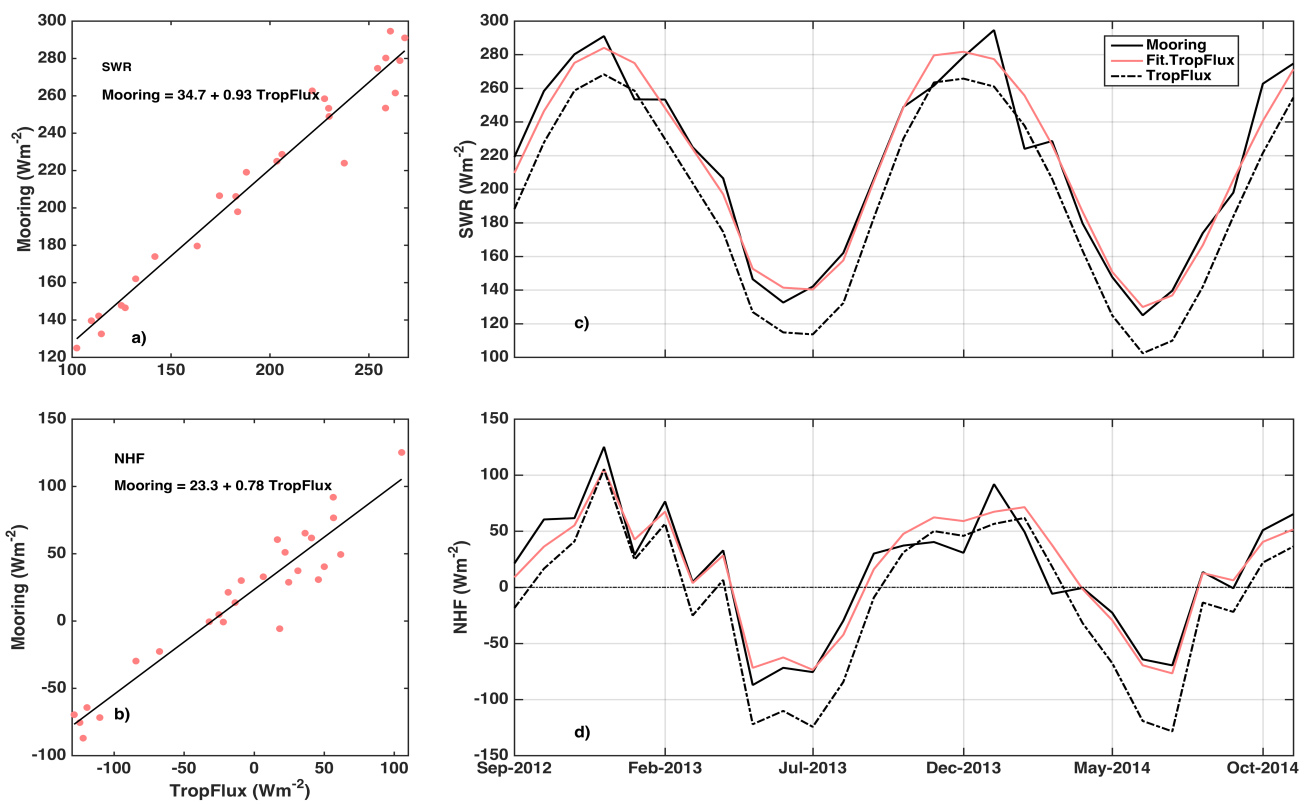

Figure 12. Linear regression (left panels) between mooring and TropFlux shortwave radiation and net heat flux and the fitted TropFlux fluxes with mooring and the actual TropFlux fluxes (right panels).

\subsection{Heat balance around the mooring}

Here we compare the seasonal cycle of 2-year mooring heat fluxes with the seasonal cycles of a) area averaged fluxes during $2004-2015$ and b) fluxes at the mooring location for the mooring period from the spatial analysis (Figure 15). The seasonal cycle of $Q_{t}$ in all cases shows net cooling in the mixed layer during austral winter and net warming in austral summer (Figure 15 a). The areal average of $Q_{t}$ shows more warming than that at the mooring location during April - June and November - December. The $Q_{n e t}$ cycles are very similar from the three analyses with only a small residual since we did the adjustment to the TropFlux surface fluxes. The $Q_{t}$ term is in phase with the $Q_{n e t}$ suggesting that the surface fluxes play an important role in driving the mixed layer heat storage. The areal average of $Q_{u}$ shows a net cooling throughout most of the year except a slight warming in August and September. At the mooring location, the $Q_{u}$ warms the mixed layer except during January - March. The $Q_{v}$ term maintains the 2 cycle per year variability in all cases 

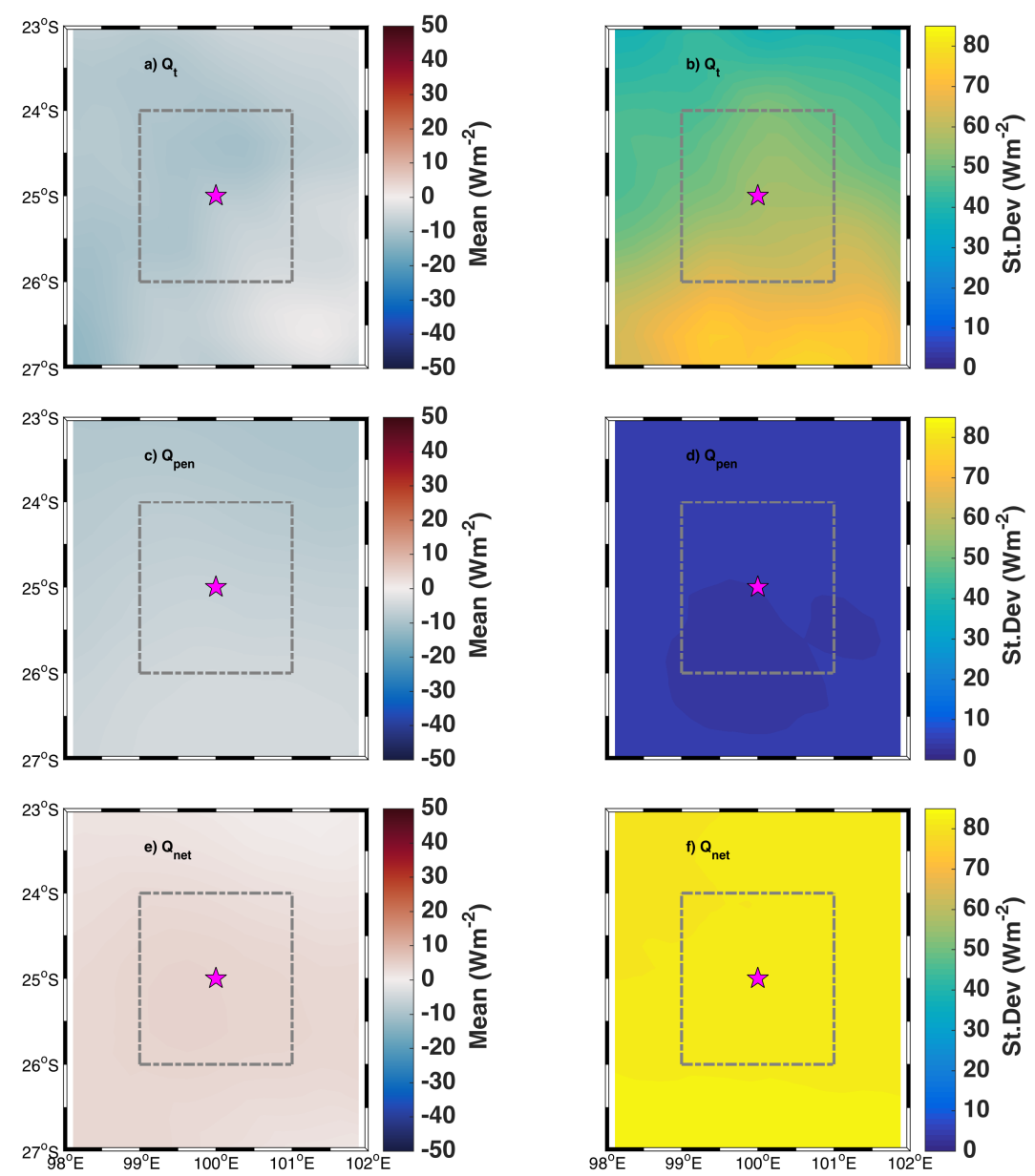

Figure 13. Annual mean (left panels) and standard deviation (right panels) of $Q_{t}, Q_{p e n}$, and $Q_{n e t}$ for the period $2004-2015$. The box encloses the region over which the seasonality of the heat budget terms are analyzed. The star represents the location of the mooring.

with peak warming during austral summer and winter. The areal average of $Q_{v}$ shows net warming throughout the year whereas it cools the mixed layer during austral spring and autumn at the mooring location.

The $Q_{\text {res }}$ flux at the mooring location shows similar seasonal cycle with variations in magnitude. The areal average has comparatively weak seasonal cycle. The spatial budget from the regional analysis for 12 years and for the mooring period suggest strong vertical processes at work during austral summer and winter in agreement with the conclusion that we obtained from the mooring analysis. The cooling from the residual is stronger from the mooring analysis than that from the regional analysis during May - December. We also 

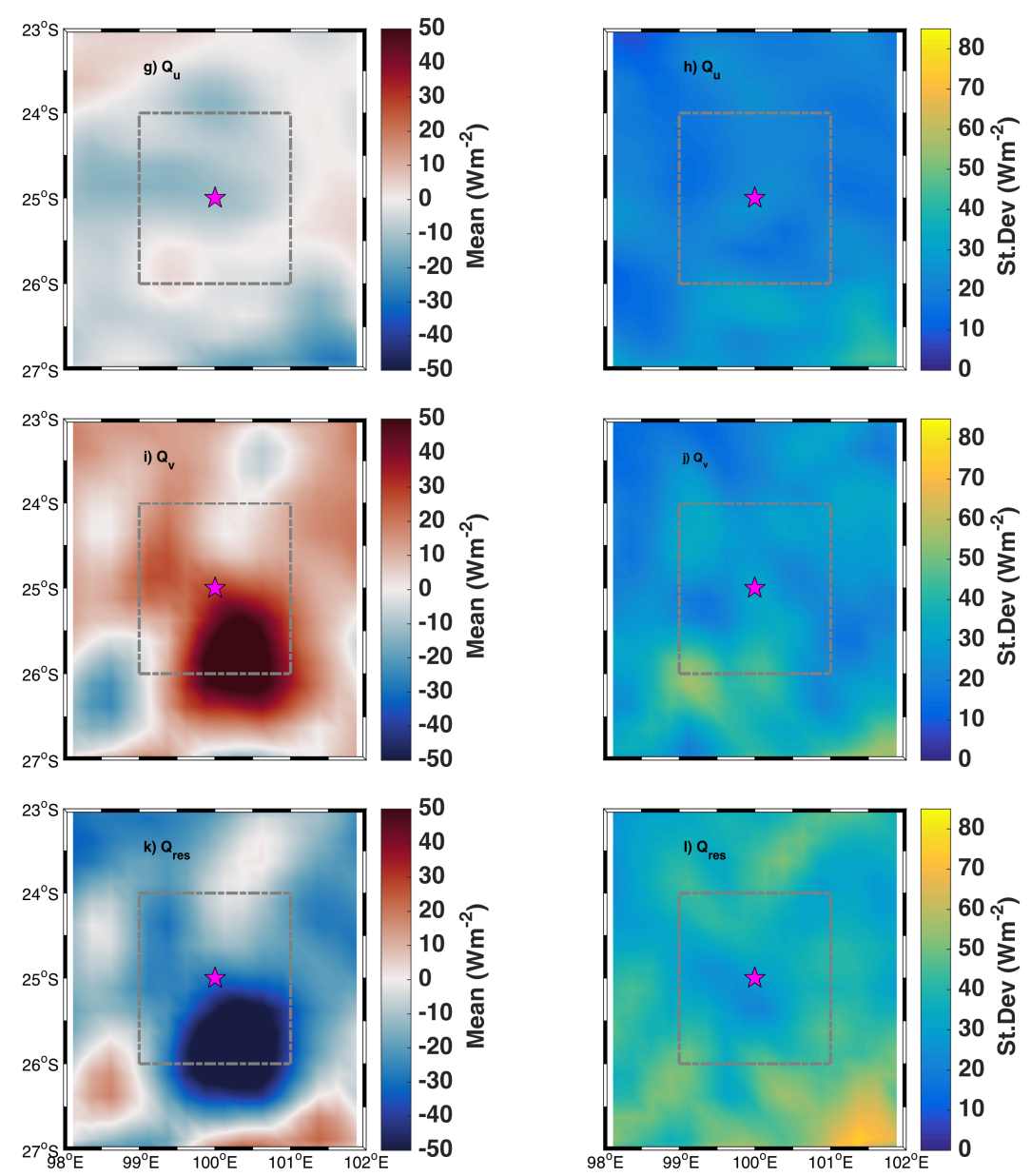

Figure 14. Same as in Fig.13 but for $Q_{u}, Q_{v}$, and $Q_{r e s}$.

calculated the seasonal cycle of the spatial average of entrainment flux using equation 12 and found it to be very small (not shown). It is possible that entrainment calculated from the gridded data is consistently underestimated due to any or all of the reasons mentioned in Section 4.5.

\section{Discussion and conclusions}

In this study, we have quantified the seasonal heat budget of the mixed layer in the southeast Indian Ocean at $25^{\circ} \mathrm{S}, 100^{\circ} \mathrm{E}$ for the first time using in situ observations. This region is characterized by year-long Ekman downwelling and strong air-sea fluxes. For this study, the rate of change of heat storage and air-sea fluxes were obtained primarily from the RAMA mooring at $25^{\circ} \mathrm{S}, 100^{\circ} \mathrm{E}$ and the horizontal advection terms were estimated using 

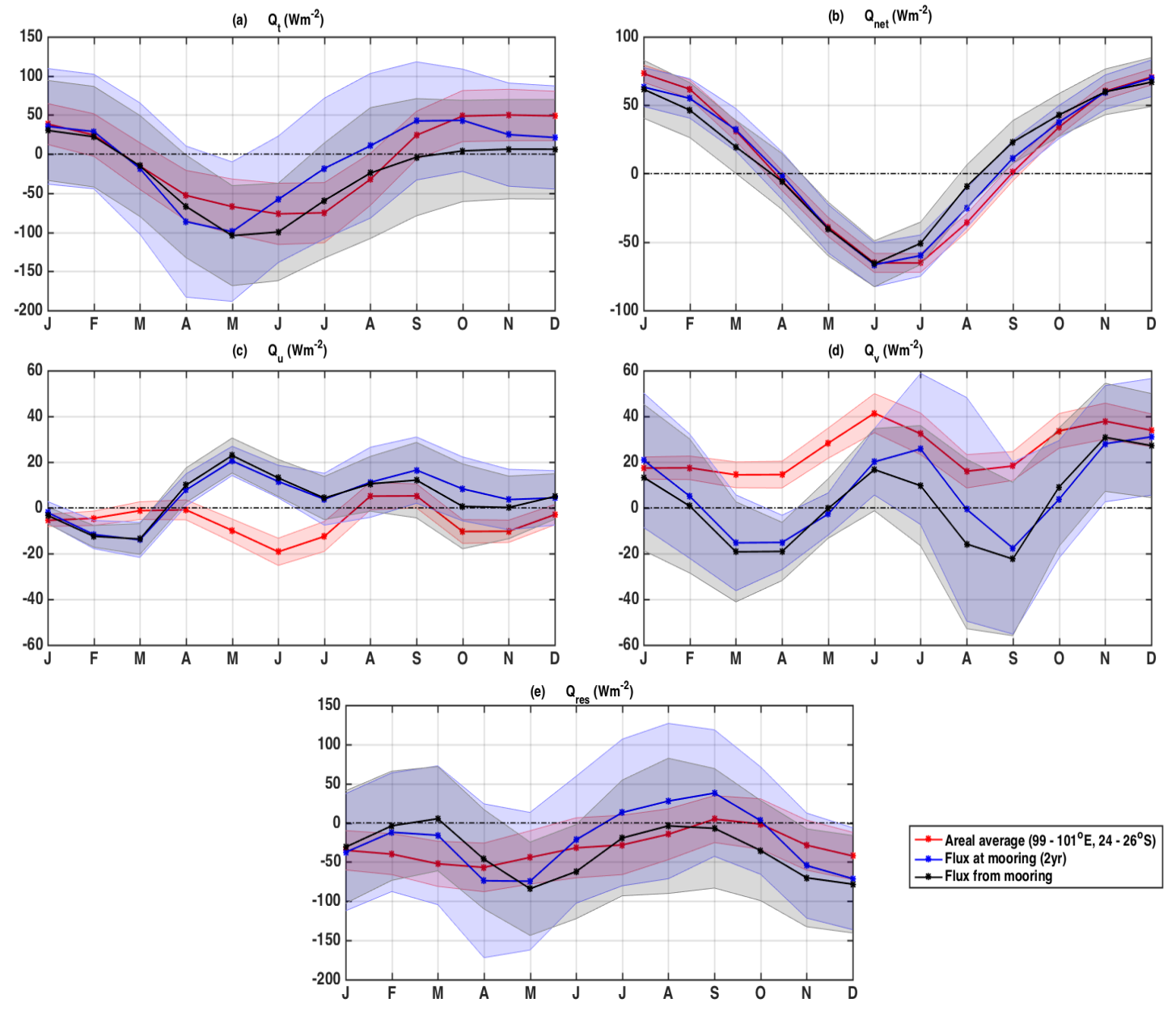

Figure 15. Seasonality of a) $Q_{t}$, b) $Q_{n e t}$, c) $Q_{u}$, d) $Q_{v}$ and e) $Q_{r e s}$ overlaid with standard error shading which in great part represents interannual variability. Note that the vertical axes are different. The red line in all plots is the areal average of heat fluxes in a $2^{\circ} \times 2^{\circ}$ box around the mooring location during $2004-2015$. The seasonality of heat fluxes interpolated at the mooring location for the mooring period is shown in blue. The black line is the seasonality of heat fluxes from the mooring observations. All seasonal cycles are filtered with a 1-2-1 running mean filter.

Reynolds SST and OSCAR velocities. The vertical heat fluxes through the base of the mixed layer are estimated as a residual. Assuming that the errors in estimating the heat budget terms are correctly characterised in Figure 5, the residual can be interpreted as comprising of turbulent heat diffusion, vertical advection, lateral induction, entrainment and neglected physical processes. The heat budget from the 2-year in situ data is complemented by a heat 
budget calculated using a 12-year time series from the TropFlux reanalysis and Argo, both at the mooring location and in a $2^{\circ} \times 2^{\circ}$ box around the mooring. After first correcting the reanalysis surface fluxes using the observed fluxes at the mooring, this analysis provides a longer term context for understanding the processes that drive the surface layer heat budget in this region.

We have shown that the mixed layer heat balance in this region is dominated by surface net heat flux. Despite the uncertainties in the entrainment calculation, it has a good agreement with the residual especially during austral summer, autumn and early austral winter. For most of the year, the vertical subsurface fluxes contribute more to the mixed layer heat balance than the horizontal advection, which is influenced by eddies and possibly annual and semi-annual Rossby waves. Of the surface heat fluxes, $Q_{S W}$ and $Q_{L}$ are the two dominant terms. The contribution of $Q_{L W}$ and $Q_{S}$ to $Q_{n e t}$ is comparatively small. The $Q_{n e t}$ tends to warm the mixed layer during austral summer and cool during austral winter. The penetrative component of short wave radiation is a large term in the balance during austral summer when the mixed layer is shallow. Among the heat budget terms in Figure 5, zonal advection makes the smallest contribution to the mixed layer heat balance. It warms the mixed layer throughout the year except during January - March. Meridional advection has more influence on the mixed layer temperature by warming the mixed layer during austral winter and summer and cooling it during austral spring and autumn. During austral summer, all heat flux terms tend to warm the mixed layer, with $Q_{n e t}$ and $Q_{v}$ contributing more compared to $Q_{u}$. The cooling by vertical processes keeps the mixed layer temperature from becoming even warmer. During winter, horizontal advection of heat tends to warm the mixed layer whereas the $Q_{n e t}$ and vertical processes cool the mixed layer.

As discussed in WM99, horizontal advection seems to be sensitive to the location and the time period for which it is calculated (Figure 14g-j). At the mooring location, the meridional advection has a 2 cycle per year variability. The warming by meridional advection during winter may be associated with generation of eddies due to local baroclinic instability near the mooring (Jia et al., 2011). The warming by meridional advection in austral summer could be due to the arrival of LC eddies 6 months after they form at the coast during winter when the LC is strongest and most baroclinically unstable (Feng et al., 2007, 2003). Westward propagating annual and semi-annual Rossby waves (Morrow \& Birol, 1998) may also contribute to both summer and winter peaks in heat advection. The variability of the 
geostrophic current is larger than that of the Ekman current suggesting that the geostrophic component of velocity dominates meridional advection in the mixed layer. The seasonality of meridional advection at the mooring location is quite different from that in the $\mathrm{LC}$ region in an eddy resolving model (Feng et al., 2008). However, the model agrees with the mooring analysis that meridional advection is one of the dominant terms in driving the mixed layer temperature in spite of the large uncertainties. The residual from the mooring analysis has a 2 cycle per year variability which mainly reflects the fact that the total advection has two large warming phases and two much weaker and time-compressed cooling phases.

The strong seasonal cycle of $Q_{n e t}$ in this subtropical region with warming in austral summer and strong cooling in austral winter is quite different to that found in the tropics where $Q_{n e t}$ is warming throughout the year (Foltz et al., 2010; Vialard, Foltz, McPhaden, Duvel, \& Montegut, 2008; Wang \& McPhaden, 1999; Yu et al., 2007). The meridional advection term is found to be a significant contributor to the heat balance in both equatorial and subtropical zone heat budget studies; these include the equatorial Pacific, where meridional heat advection is mainly due to tropical instability waves (Wang \& McPhaden, 1999), and the southwestern tropical Indian Ocean due to strong seasonally varying surface currents and SST gradients (Foltz et al., 2010), and the subtropical convergence zone of the North Atlantic due to northward advection of fronts (Rudnick \& Weller, 1993). In our study of the eastern subtropical Indian Ocean, we suggest that the meridional heat advection is dominated by eddy fluxes and annual and semi-annual Rossby waves at the mooring location.

There are a number of limitations to this study. The unavailability of direct velocity measurements from the mooring made it difficult to estimate the advection terms accurately. In place of mooring velocities, we used 5-day OSCAR currents interpolated to a daily time step to match the mooring time series. This may result in an overestimation of the uncertainty of the OSCAR product. Also due to the lack of subsurface velocity observations at the mooring, we neglected the shear across the base of the mixed layer when estimating entrainment velocity, which is a key source of turbulence. This resulted in underestimating the corresponding entrainment flux.

As discussed above, the ocean dynamics in this region are quite different from other regions where the heat budget has been analyzed. The interaction between the eastward flowing SICC and westward propagating mesoscale eddies/Rossby waves in this region makes 
the ocean dynamics very complex. Vertical processes were not well resolved in our study, hence potentially important subsurface fluxes originating from meso-to-submesoscale eddy activity (Cummins, Masson, \& Saenko, 2016; Griffies et al., 2015; Morrison, Saenko, Hogg, \& Spence, 2013) and subduction (Spall, Weller, \& Furey, 2000) of Subtropical Water are unaccounted for. Future analysis of a high-resolution, well-validated dynamical model that captures these interactions is required to fully resolve the processes responsible for modifying the mixed layer temperature in this region.

\section{Acknowledgments}

We acknowledge the efforts of the individuals, particularly Eric Schulz, who worked for many years to achieve this short-lived deployment of the RAMA $25^{\circ} \mathrm{S}$ mooring, that was inspired by Fritz Schott for inclusion in RAMA. We would like to thank the providers of Argo, SODA, TropFlux, NOAA High Resolution SST and OSCAR data, without which the in situ mooring analysis would not have been possible. Mooring data is freely available from the PMEL Global Tropical Moored Buoy Array website. TropFlux data is available from the ESSO-Indian National Centre for Ocean Information Services (INCOIS) website. AsiaPacific Data-Research Centre (APDRC) provides SODA and OSCAR data. The Argo data were collected and made freely available by the International Argo Program and the national programs that contribute to it (http://www.argo.ucsd.edu, http://doi.org/10.17882/ 42182). NOAA High Resolution SST data is provided by the NOAA/OAR/ESRL PSD, Boulder, Colorado, USA, in their website at https://www.esrl.noaa.gov/psd/. We would also like to thank the three reviewers for their careful and constructive comments on the earlier versions of this manuscript. A.C acknowledges the support from the Quantitative Marine Science (QMS) program, a joint program between the University of Tasmania and CSIRO. H.P and N.B acknowledge support from ARC Discovery Project DP130102088 and the Australian Government Department of the Environment and Energy National Environmental Science Programme (NESP). M.F acknowledges the support from CSHOR, a joint initiative between the Qingdao National Laboratory for Marine Science and Technology (QNLM), CSIRO, University of New South Wales and University of Tasmania. This is Pacific Marine Environmental Laboratory (PMEL) contribution number 4831.

\section{References}

Bond, N. A., \& McPhaden, M. J. (1995, September). An indirect estimate of the diurnal 
cycle in upper ocean turbulent heat fluxes at the equator, 140-degrees-w. J. Geophys. Res.-Oceans, $100(\mathrm{C} 9), 18369-18378$.

Carton, J. A., \& Giese, B. S. (2008, August). A reanalysis of ocean climate using simple ocean data assimilation (soda). Mon. Weather Rev., 136(8), 2999-3017. doi: 10.1175/ 2007MWR1978.1

Chelton, D. B., Schlax, M. G., Samelson, R. M., \& de Szoeke, R. A. (2007, August). Global observations of large oceanic eddies. Geophys. Res. Lett., 34(15). doi: 10.1029/ 2007GL030812

Cronin, M. F., Pelland, N. A., Emerson, S. R., \& Crawford, W. R. (2015, November). Estimating diffusivity from the mixed layer heat and salt balances in the north pacific. J. Geophys. Res.-Oceans, 120(11), 7346-7362. doi: 10.1002/2015JC011010

Cummins, P. F., Masson, D., \& Saenko, O. A. (2016, June). Vertical heat flux in the ocean: Estimates from observations and from a coupled general circulation model. $J$. Geophys. Res.-Oceans, 121(6), 3790-3802. doi: 10.1002/2016JC011647

Divakaran, P., \& Brassington, G. B. (2011, January). Arterial ocean circulation of the southeast indian ocean. Geophys. Res. Lett., 38(L01802). doi: 10.1029/2010GL045574

Domingues, C. M., Maltrud, M. E., Wijffels, S. E., Church, J. A., \& Tomczak, M. (2007). Simulated lagrangian pathways between the leeuwin current system and the upperocean circulation of the southeast indian ocean. Deep-Sea Res. Part II-Top. Stud. Oceanogr., 54(8-10), 797-817. doi: 10.1016/j.dsr2.2006.10.003

Fairall, C. W., Bradley, E. F., Rogers, D. P., Edson, J. B., \& Young, G. S. (1996, February). Bulk parameterization of air-sea fluxes for tropical ocean global atmosphere coupled ocean atmosphere response experiment. J. Geophys. Res.-Oceans, 101(C2), 37473764 .

Fang, F., \& Morrow, R. (2003). Evolution, movement and decay of warm-core leeuwin current eddies. Deep Sea Research Part II: Topical Studies in Oceanography, 50(1213), 2245-2261.

Feng, M., Biastoch, A., Boening, C., Caputi, N., \& Meyers, G. (2008, December). Seasonal and interannual variations of upper ocean heat balance off the west coast of australia. J. Geophys. Res.-Oceans, 113(C12). doi: 10.1029/2008JC004908

Feng, M., Hendon, H. H., Xie, S.-P., Marshall, A. G., Schiller, A., Kosaka, Y., ... Pearce, A. (2015, January). Decadal increase in ningaloo nino since the late 1990s. Geophys. Res. Lett., 42(1), 104-112. doi: 10.1002/2014GL062509 
Feng, M., Majewski, L. J., Fandry, C. B., \& Waite, A. M. (2007). Characteristics of two counter-rotating eddies in the leeuwin current system off the western australian coast. Deep-Sea Res. Part II-Top. Stud. Oceanogr., 54(8-10), 961-980. doi: 10.1016/ j.dsr2.2006.11.022

Feng, M., McPhaden, M. J., Xie, S.-P., \& Hafner, J. (2013, February). La nina forces unprecedented leeuwin current warming in 2011. Sci Rep, 3(1277). doi: 10.1038/ srep01277

Feng, M., Meyers, G., Pearce, A., \& Wijffels, S. (2003, November). Annual and interannual variations of the leeuwin current at 32 degrees s. J. Geophys. Res.-Oceans, 108(C11). doi: 10.1029/2002JC001763

Foltz, G. R., \& McPhaden, M. J. (2008, February). Seasonal mixed layer salinity balance of the tropical north atlantic ocean. J. Geophys. Res.-Oceans, 113(C2). doi: 10.1029/ 2007JC004178

Foltz, G. R., Vialard, J., Kumar, B. P., \& McPhaden, M. J. (2010, February). Seasonal mixed layer heat balance of the southwestern tropical indian ocean. J. Clim., 23(4), 947-965. doi: 10.1175/2009JCLI3268.1

Godfrey, J. S. (1996, May). The effect of the indonesian throughflow on ocean circulation and heat exchange with the atmosphere: A review. J. Geophys. Res.-Oceans, 101(C5), $12217-12237$.

Godfrey, J. S., \& Ridgway, K. R. (1985). The large-scale environment of the polewardflowing leeuwin current, western-australia - longshore steric height gradients, wind stresses and geostrophic flow. J. Phys. Oceanogr., 15(5), 481-495.

Griffies, S. M., Winton, M., Anderson, W. G., Benson, R., Delworth, T. L., Dufour, C. O., ... Zhang, R. (2015, February). Impacts on ocean heat from transient mesoscale eddies in a hierarchy of climate models. J. Clim., 28(3), 952-977. doi: 10.1175/ JCLI-D-14-00353.1

Jia, F., Wu, L., \& Qiu, B. (2011, April). Seasonal modulation off eddy kinetic energy and its formation mechanism in the southeast indian ocean. J. Phys. Oceanogr., 41(4), 657-665. doi: 10.1175/2010JPO4436.1

Josey, S. A., Kent, E. C., \& Taylor, P. K. (1999, September). New insights into the ocean heat budget closure problem from analysis of the soc air-sea flux climatology. J. Clim., 12(9), 2856-2880.

Karstensen, J., \& Quadfasel, D. (2002). Water subducted into the indian ocean subtropical 
gyre. Deep-Sea Res. Part II-Top. Stud. Oceanogr., 49(7-8), 1441-1457.

Kim, S.-B., Lee, T., \& Fukumori, I. (2007, August). Mechanisms controlling the interannual variation of mixed layer temperature averaged over the nino-3 region. J. Clim., 20(15), 3822-3843. doi: 10.1175/JCLI4206.1

Kumar, B. P., Vialard, J., Lengaigne, M., Murty, V. S. N., \& McPhaden, M. J. (2012, April). Tropflux: air-sea fluxes for the global tropical oceans-description and evaluation. Clim. Dyn., 38(7-8), 1521-1543. doi: 10.1007/s00382-011-1115-0

Lee, T. (2004, September). Decadal weakening of the shallow overturning circulation in the south indian ocean. Geophys. Res. Lett., 31(18). doi: 10.1029/2004GL020884

McPhaden, M. J., Meyers, G., Ando, K., Masumoto, Y., Murty, V. S. N., Ravichandran, M., ... Yu, W. (2009, April). Rama the research moored array for african-asian-australian monsoon analysis and prediction. Bull. Amer. Meteorol. Soc., 90(4), 459-+. doi: 10.1175/2008BAMS2608.1

Menezes, V. V., Phillips, H. E., Schiller, A., Bindoff, N. L., Domingues, C. M., \& Vianna, M. L. (2014, October). South indian countercurrent and associated fronts. J. Geophys. Res.-Oceans, 119(10), 6763-6791. doi: 10.1002/2014JC010076

Morel, A., \& Antoine, D. (1994, July). Heating rate within the upper ocean in relation to its biooptical state. J. Phys. Oceanogr., 24(7), 1652-1665.

Morrison, A. K., Saenko, O. A., Hogg, A. M., \& Spence, P. (2013, October). The role of vertical eddy flux in southern ocean heat uptake. Geophys. Res. Lett., 40(20), 5445-5450. doi: 10.1002/2013GL057706

Morrow, R., \& Birol, F. (1998, August). Variability in the southeast indian ocean from altimetry: Forcing mechanisms for the leeuwin current. J. Geophys. Res.-Oceans, 103(C9), 18529-18544.

Morrow, R., Birol, F., Griffin, D., \& Sudre, J. (2004, December). Divergent pathways of cyclonic and anti-cyclonic ocean eddies. Geophys. Res. Lett., 31(24). doi: 10.1029/ 2004GL020974

Morrow, R., Fang, F. X., Fieux, M., \& Molcard, R. (2003). Anatomy of three warmcore leeuwin current eddies. Deep-Sea Res. Part II-Top. Stud. Oceanogr., 50(12-13), 2229-2243. doi: 10.1016/S0967-0645(03)00054-7

Niiler, P. P. (1977). One-dimensional models of the upper ocean. Modelling and Prediction of the Upper Layers of the Ocean, 143-172. Retrieved from https://ci.nii.ac.jp/ naid/10025553601/en/ 
Palastanga, V., van Leeuwen, P. J., Schouten, M. W., \& P. M. de Ruijter, W. (2007, January). Flow structure and variability in the subtropical indian ocean: Instability of the south indian ocean countercurrent. J. Geophys. Res.-Oceans, 112(C1). doi: 10.1029/2005JC003395

Pearce, A., \& Feng, M. (2007). Observations of warming on the western australian continental shelf. Mar. Freshw. Res., 58(10), 914-920. doi: 10.1071/MF07082

Fairall, C., Barnier, B., Berry, D., Bourassa, M., Bradley, F., Clayson, C., .. others (2010). Observations to quantify air-sea fluxes and their role in climate variability and predictability. Proceedings of OceanObs, 9, 299-313.

Roemmich, D., Johnson, G. C., Riser, S., Davis, R., Gilson, J., Owens, W. B., ... Ignaszewski, M. (2009, June). The argo program observing the global ocean with profiling floats. Oceanography, 22(2), 34-43. doi: 10.5670/oceanog.2009.36

Rudnick, D. L., \& Weller, R. A. (1993, April). The heat-budget in the north-atlantic subtropical frontal zone. J. Geophys. Res.-Oceans, 98(C4), 6883-6893.

Schott, F. A., \& McCreary, J. P. (2001). The monsoon circulation of the indian ocean. Prog. Oceanogr., 51(1), 1-123.

Siedler, G., Rouault, M., \& Lutjeharms, J. R. E. (2006, December). Structure and origin of the subtropical south indian ocean countercurrent. Geophys. Res. Lett., 33(24). doi: 10.1029/2006GL027399

Sikhakolli, R., Sharma, R., Basu, S., Gohil, B. S., Sarkar, A., \& Prasad, K. V. S. R. (2013, February). Evaluation of oscar ocean surface current product in the tropical indian ocean using in situ data. J. Earth Syst. Sci., 122(1), 187-199.

Spall, M. A., Weller, R. A., \& Furey, P. W. (2000, November). Modeling the threedimensional upper ocean heat budget and subduction rate during the subduction experiment. J. Geophys. Res.-Oceans, 105(C11), 26151-26166.

Stevenson, J. W., \& Niiler, P. P. (1983). Upper ocean heat-budget during the hawaii-totahiti shuttle experiment. J. Phys. Oceanogr., 13(10), 1894-1907.

Sun, B. M., Yu, L. S., \& Weller, R. A. (2003, February). Comparisons of surface meteorology and turbulent heat fluxes over the atlantic: Nwp model analyses versus moored buoy observations. J. Clim., 16(4), 679-695.

Sweeney, C., Gnanadesikan, A., Griffies, S. M., Harrison, M. J., Rosati, A. J., \& Samuels, B. L. (2005, June). Impacts of shortwave penetration depth on large-scale ocean circulation and heat transport. J. Phys. Oceanogr., 35(6), 1103-1119. 
Vialard, J., Foltz, G. R., McPhaden, M. J., Duvel, J. P., \& Montegut, C. d. B. (2008, October). Strong indian ocean sea surface temperature signals associated with the madden-julian oscillation in late 2007 and early 2008. Geophys. Res. Lett., 35(19). doi: 10.1029/2008GL035238

Wang, W. M., \& McPhaden, M. J. (1999, August). The surface-layer heat balance in the equatorial pacific ocean. part i: Mean seasonal cycle. J. Phys. Oceanogr., 29(8), $1812-1831$.

Wernberg, T., Smale, D. A., Tuya, F., Thomsen, M. S., Langlois, T. J., de Bettignies, T., ... Rousseaux, C. S. (2013, January). An extreme climatic event alters marine ecosystem structure in a global biodiversity hotspot. Nat. Clim. Chang., 3(1), 78-82. doi: 10.1038/NCLIMATE1627

Yu, L., Jin, X., \& Weller, R. A. (2007, July). Annual, seasonal, and interannual variability of air-sea heat fluxes in the indian ocean. J. Clim., 20(13), 3190-3209. doi: 10.1175/ JCLI4163.1

Zhang, H. M., \& Talley, L. D. (1998, October). Heat and buoyancy budgets and mixing rates in the upper thermocline of the indian and global oceans. J. Phys. Oceanogr., 28(10), 1961-1978.

Zhang, X., \& McPhaden, M. J. (2010, August). Surface layer heat balance in the eastern equatorial pacific ocean on interannual time scales: Influence of local versus remote wind forcing. J. Clim., 23(16), 4375-4394. doi: 10.1175/2010JCLI3469.1 
Figure1. 
Figure2. 


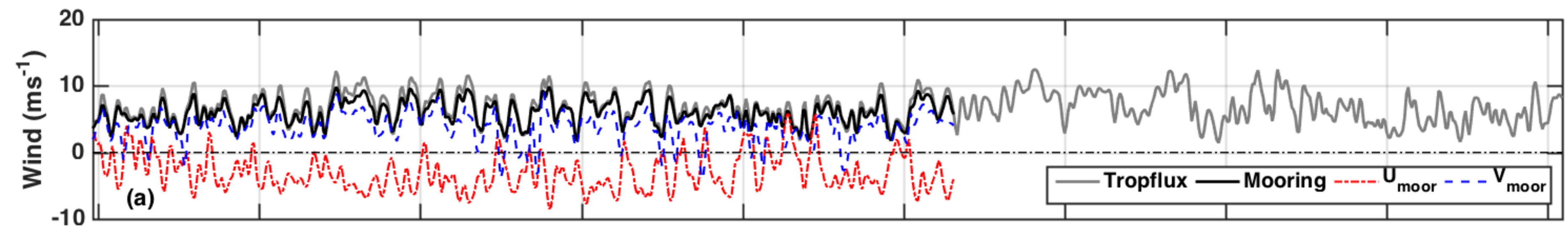

等,

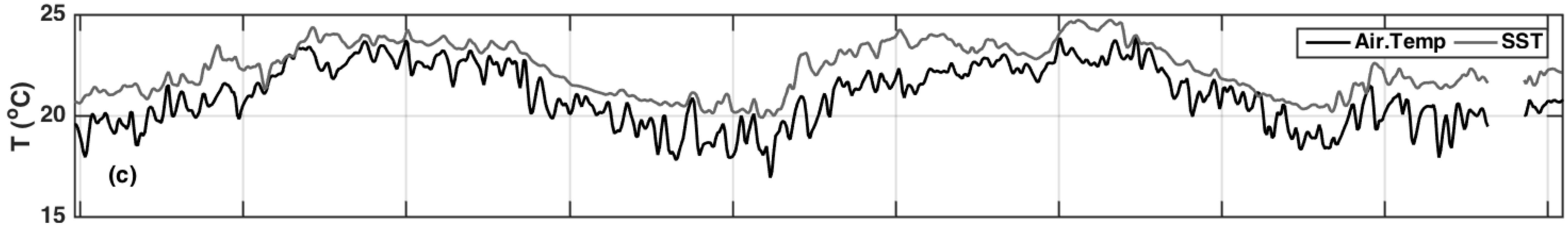
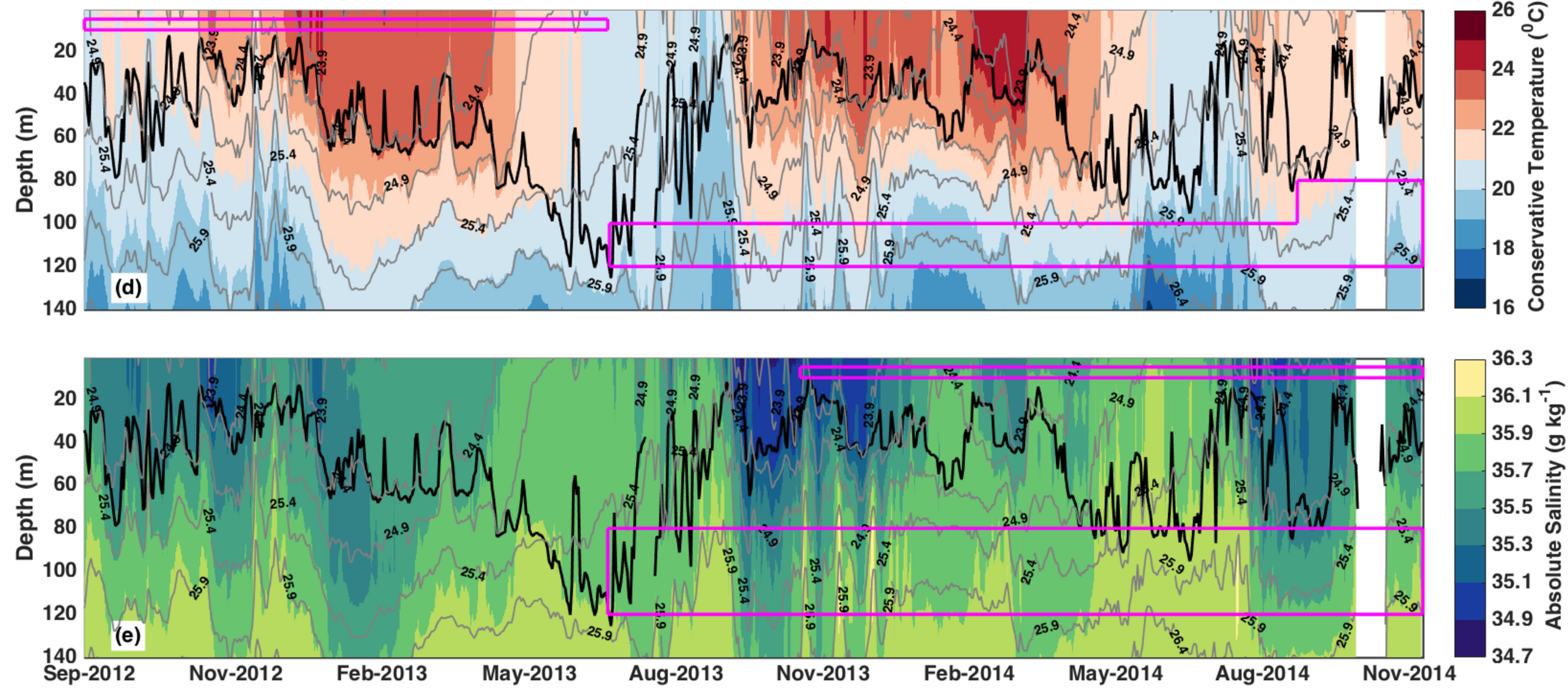
Figure3. 

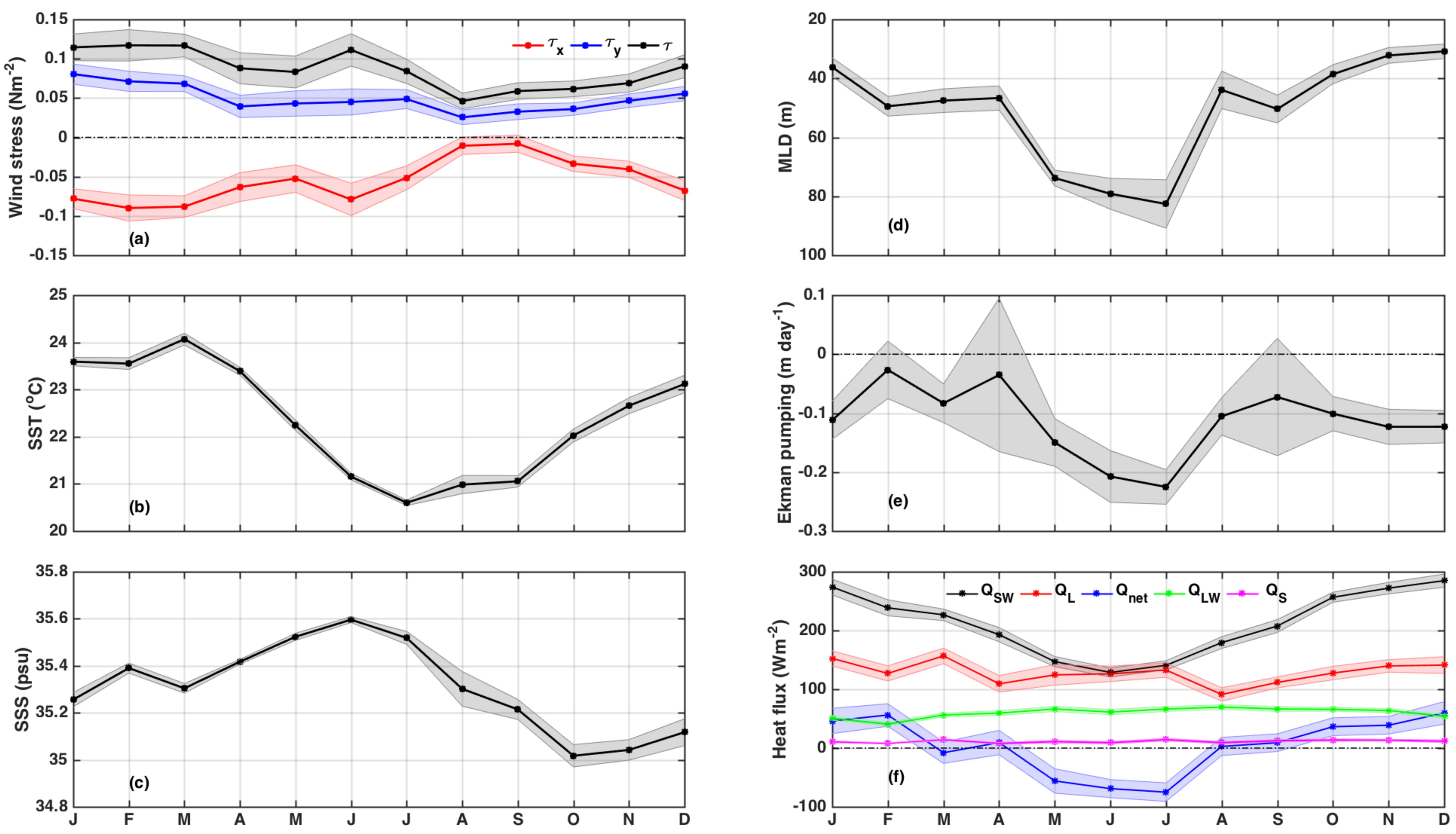
Figure4. 


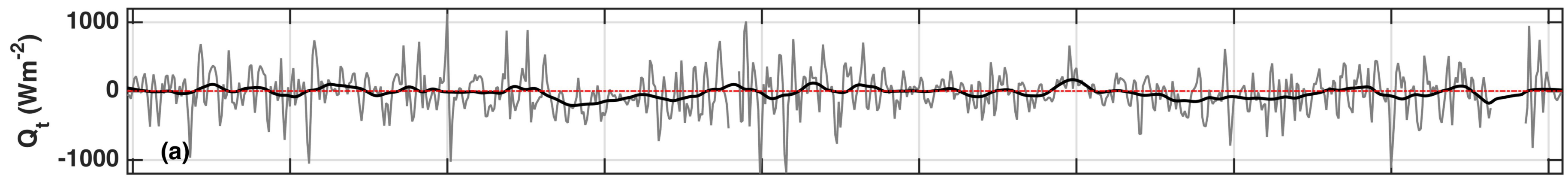

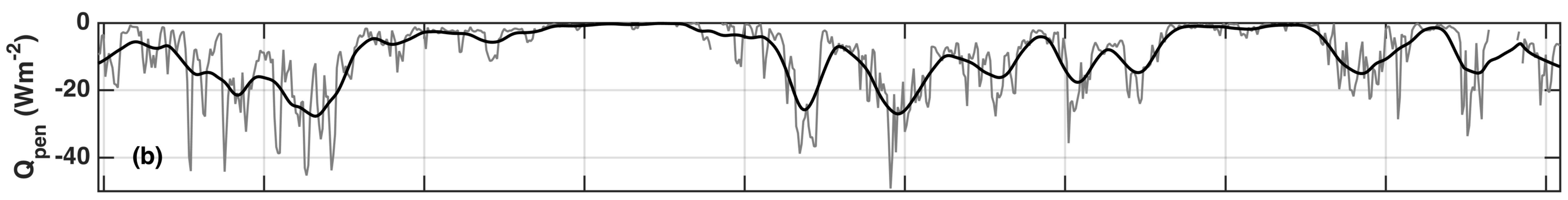

(c)
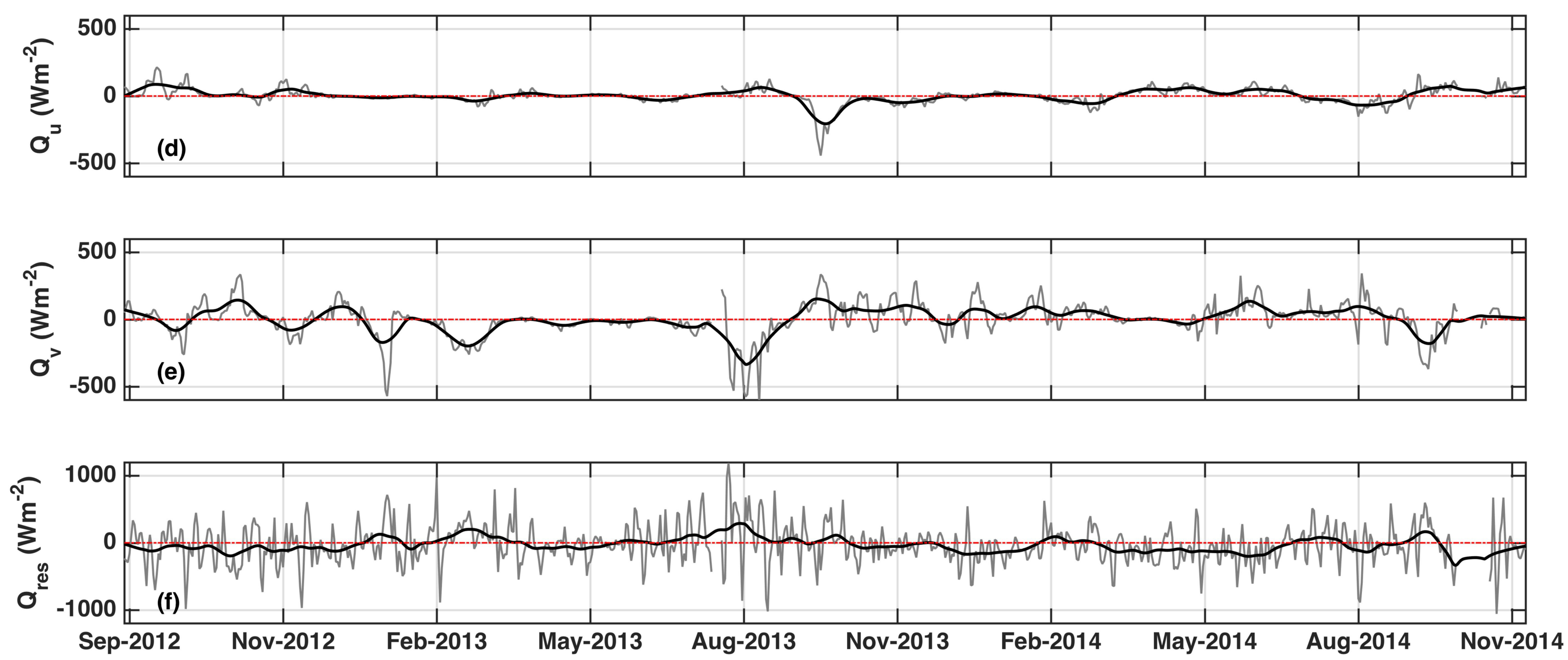
Figure5. 

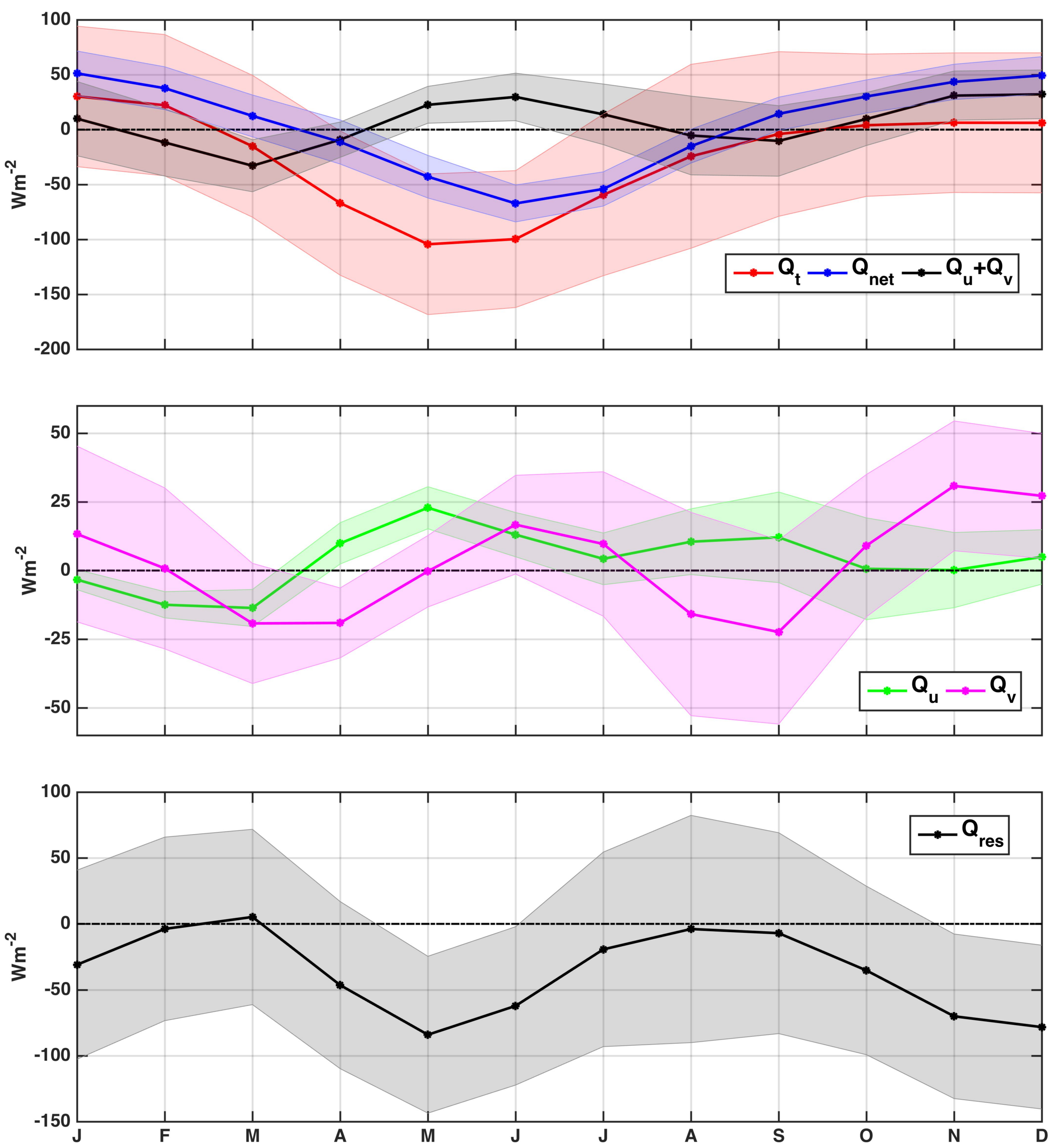
Figure6. 

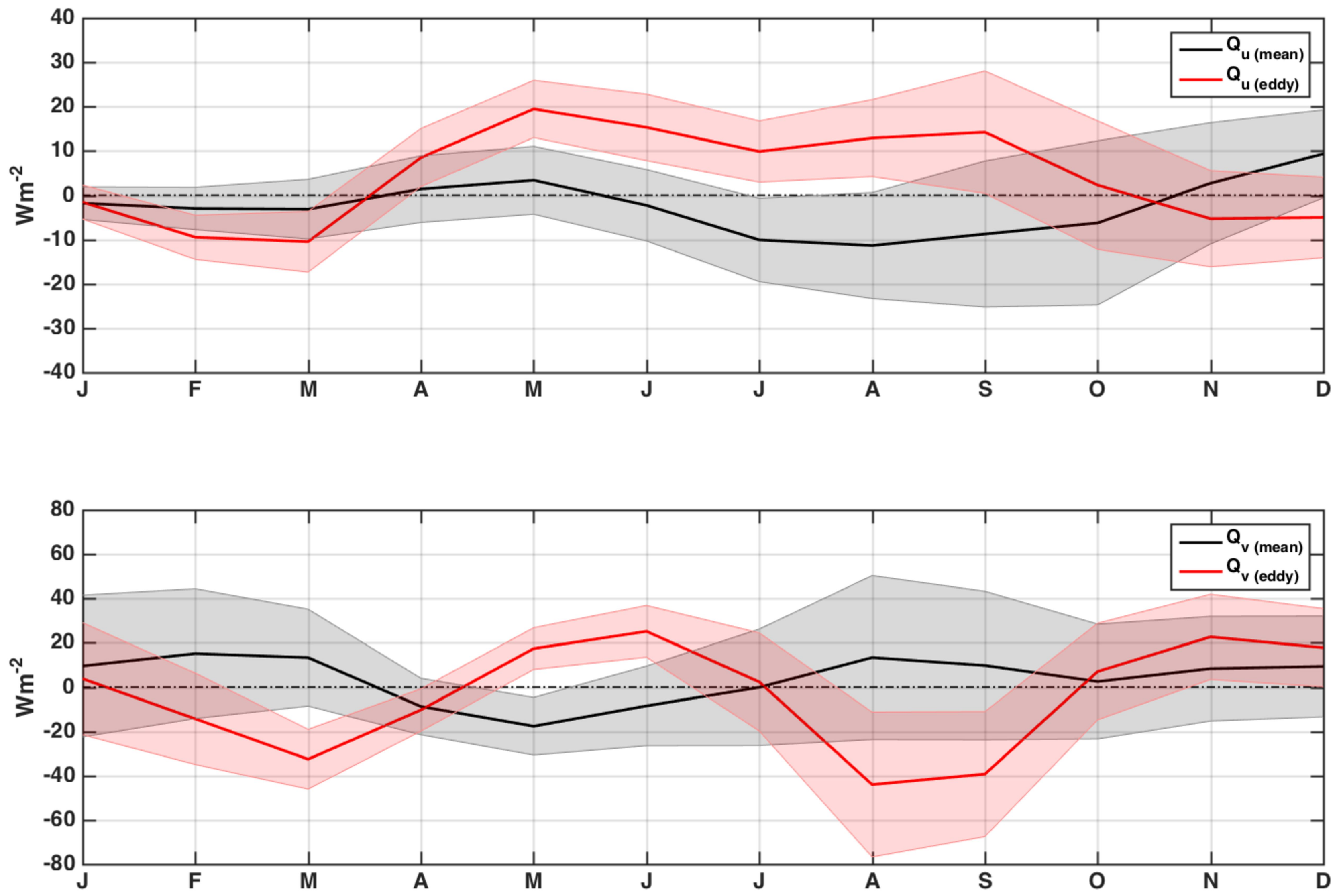
Figure7. 

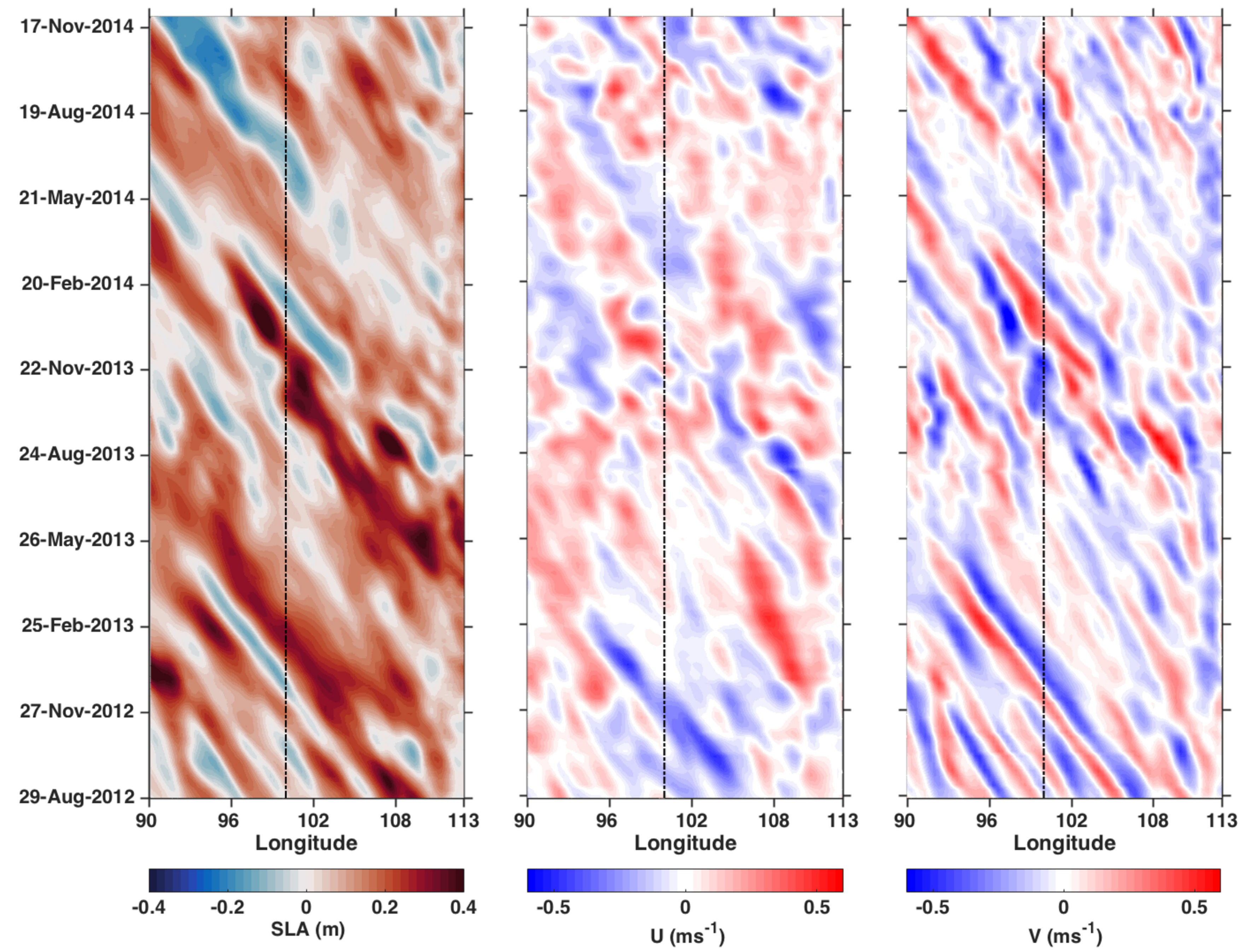
Figure8. 

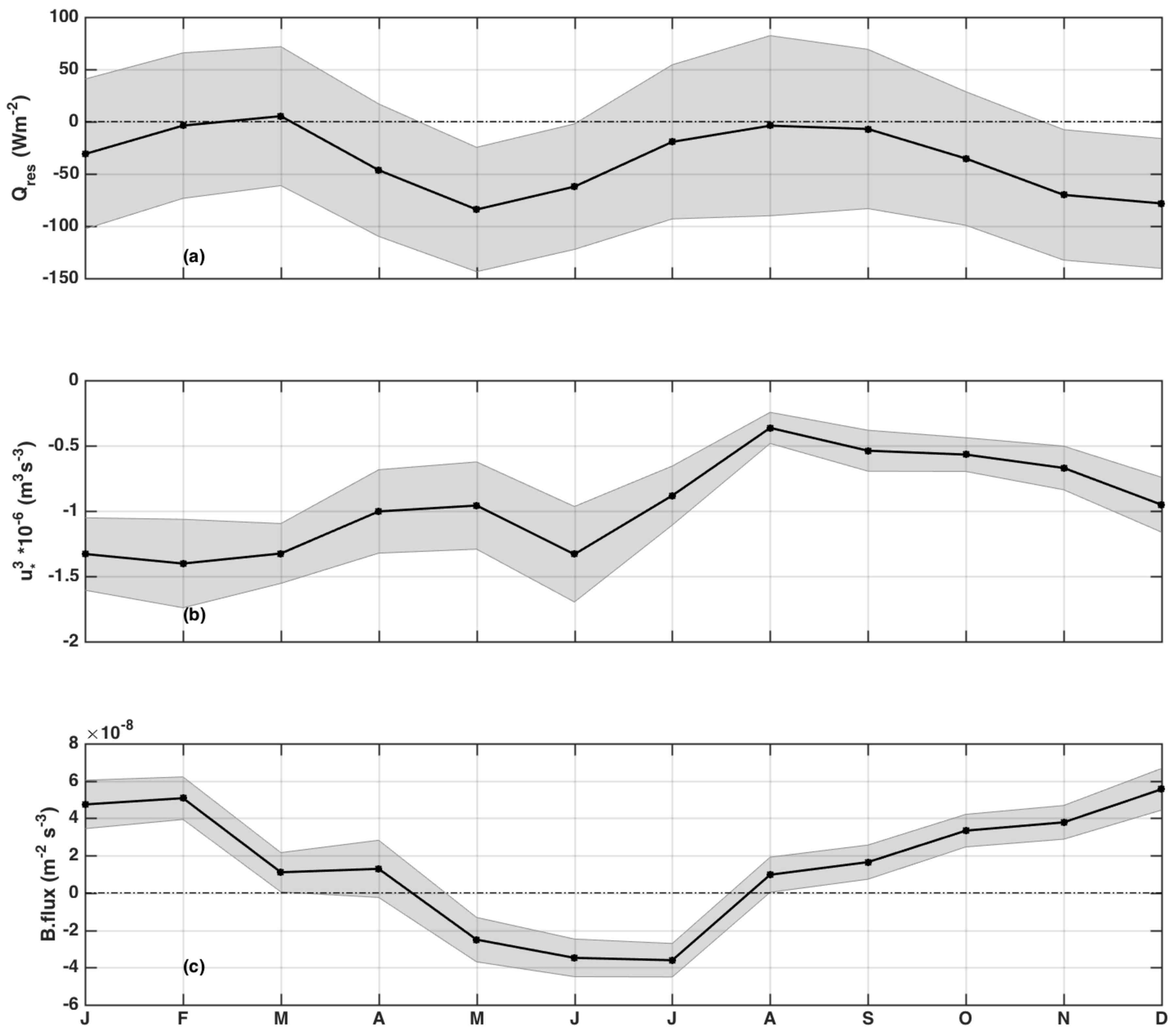
Figure9. 

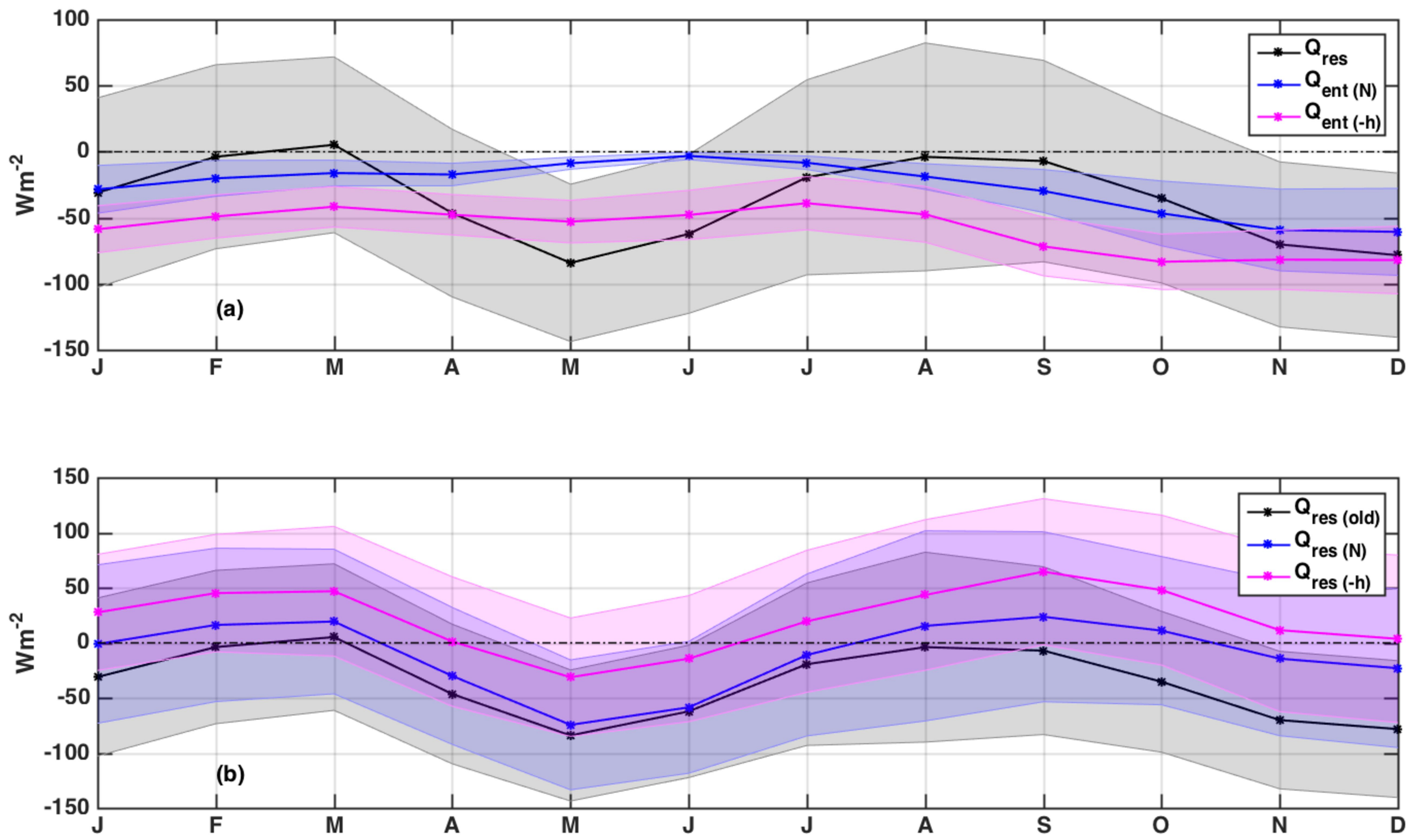
Figure10. 

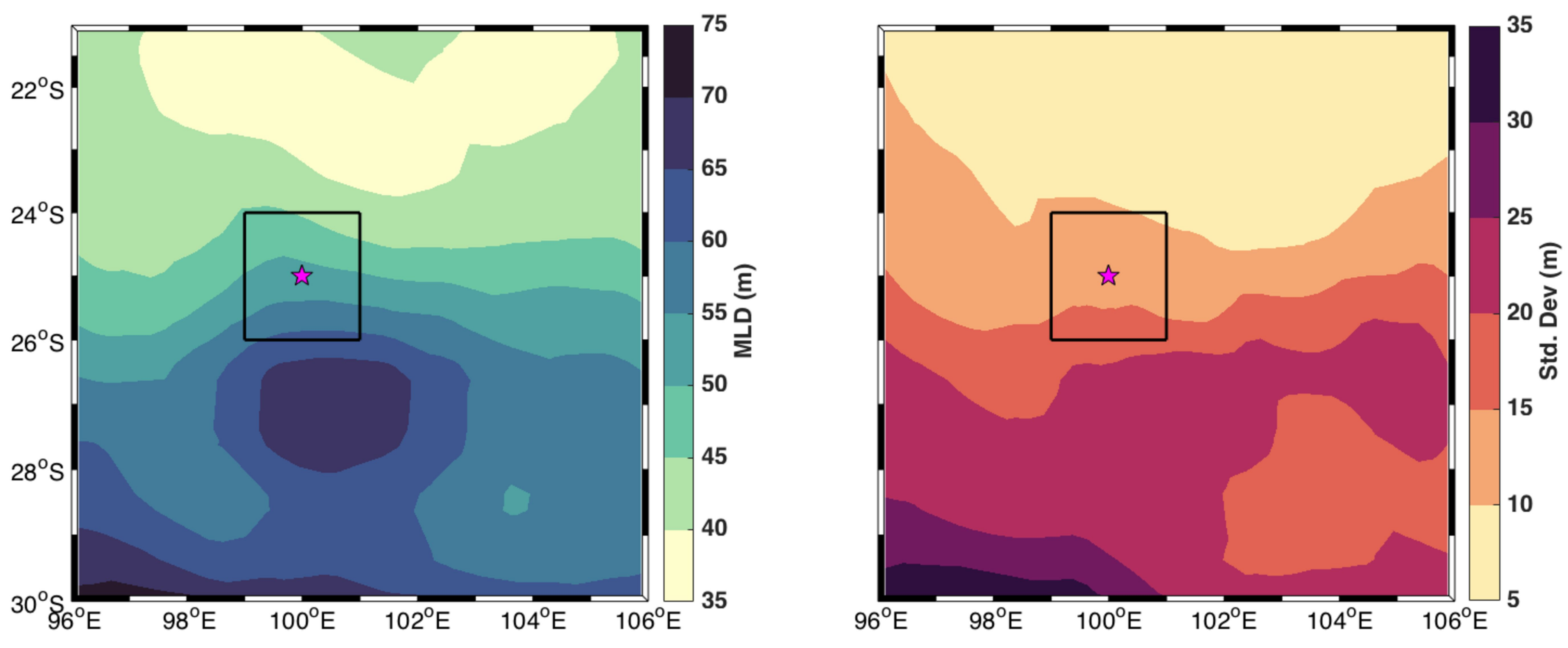
Figure11. 

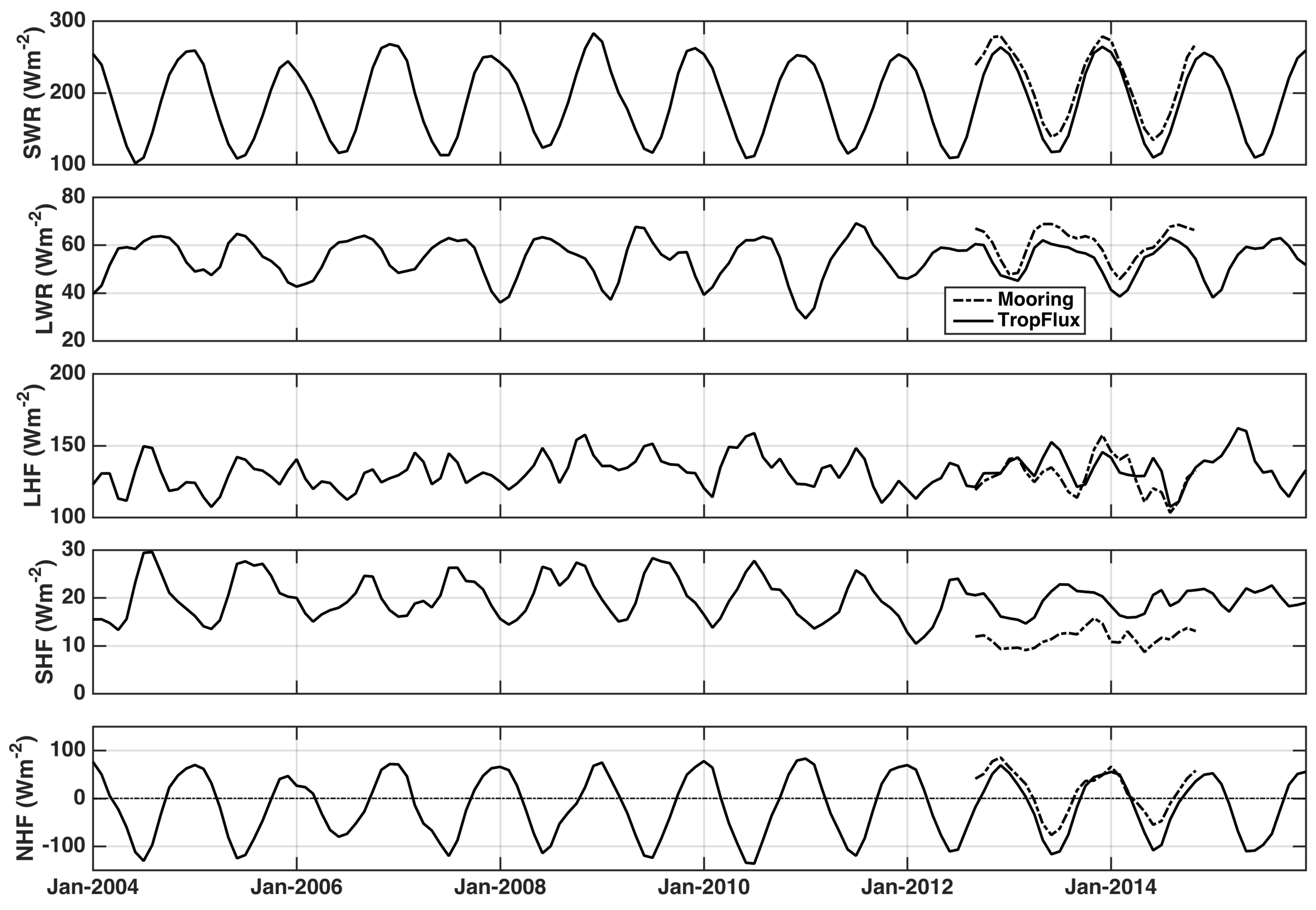
Figure12. 

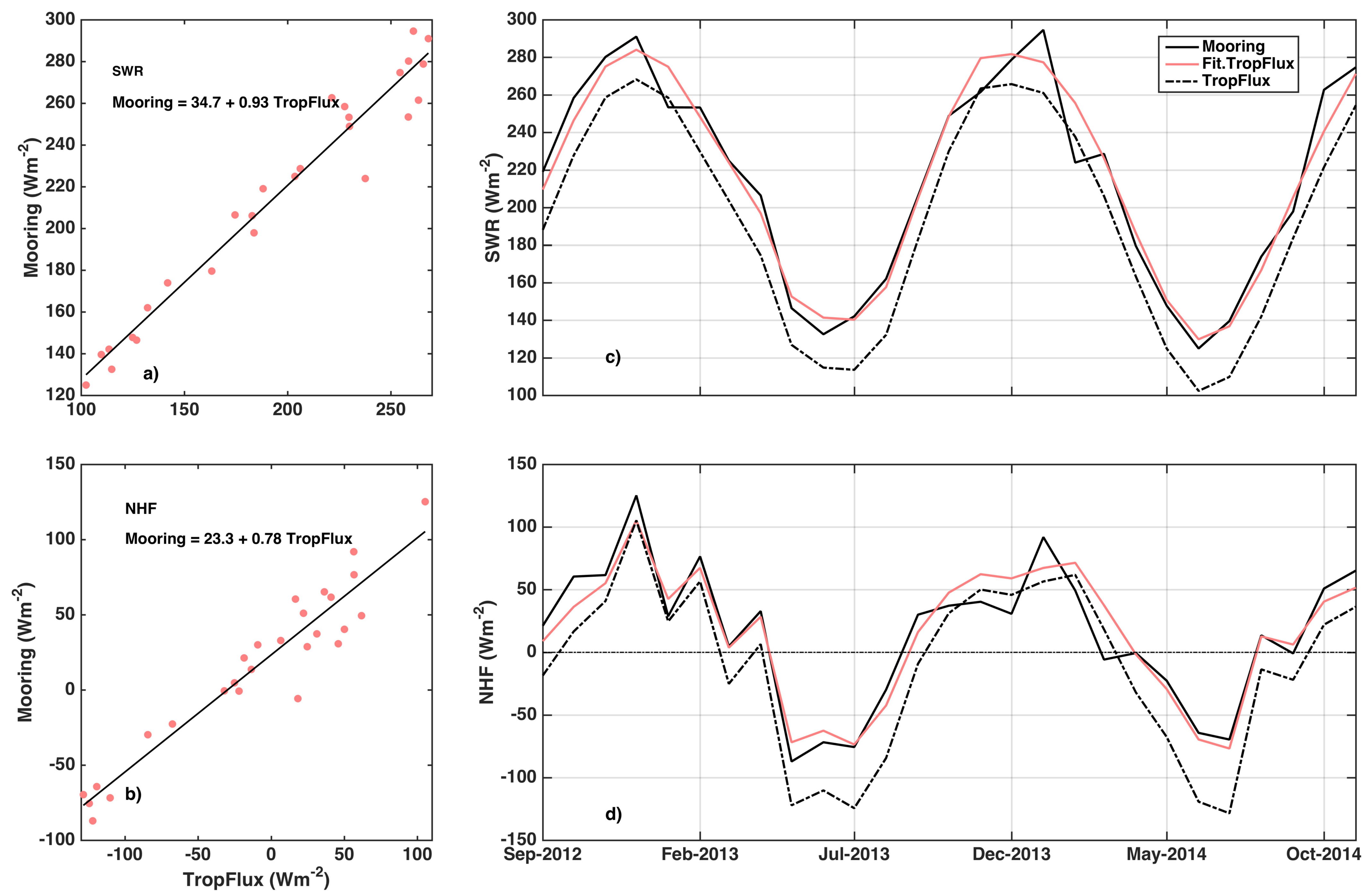
Figure13. 

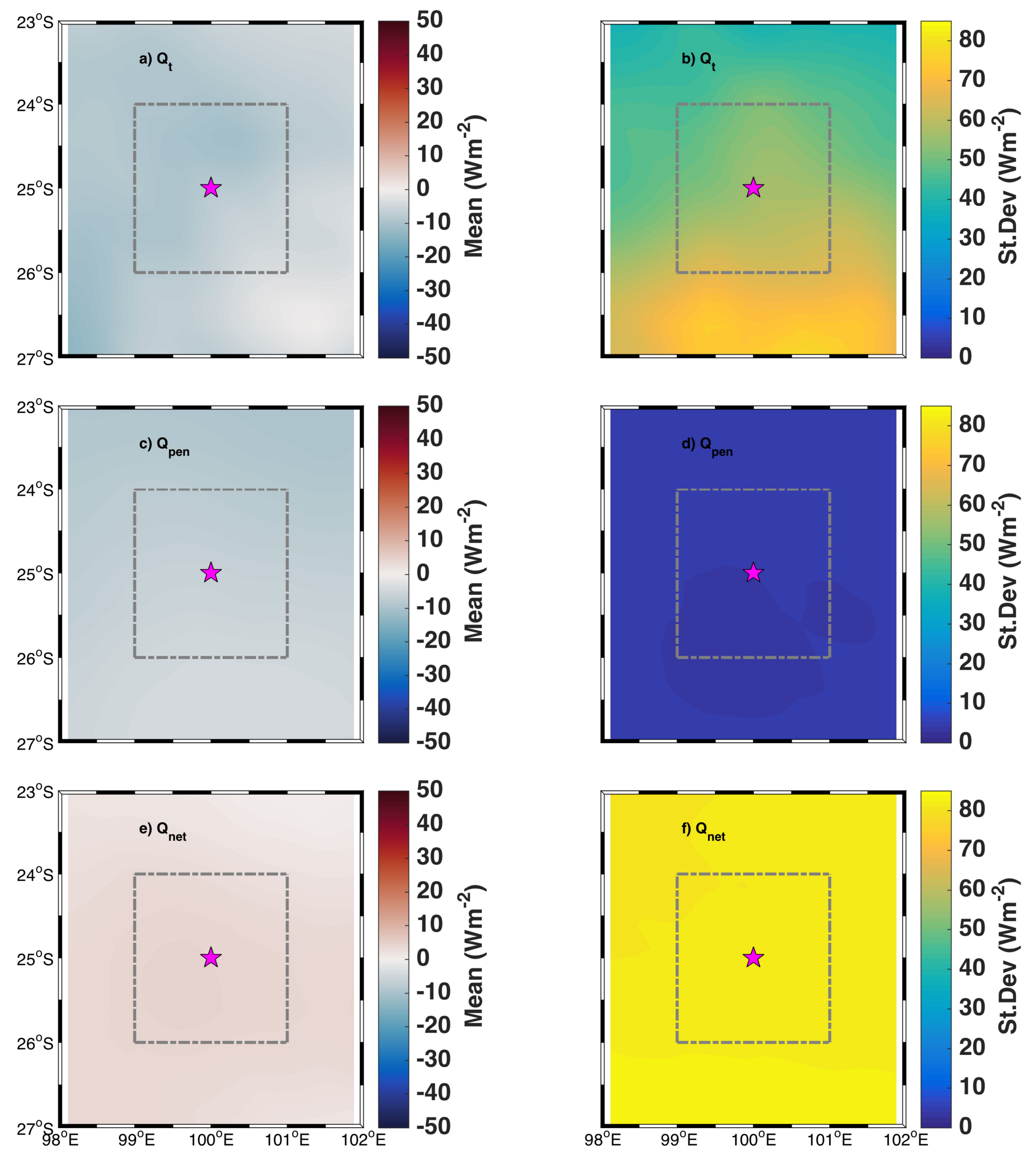
Figure14. 

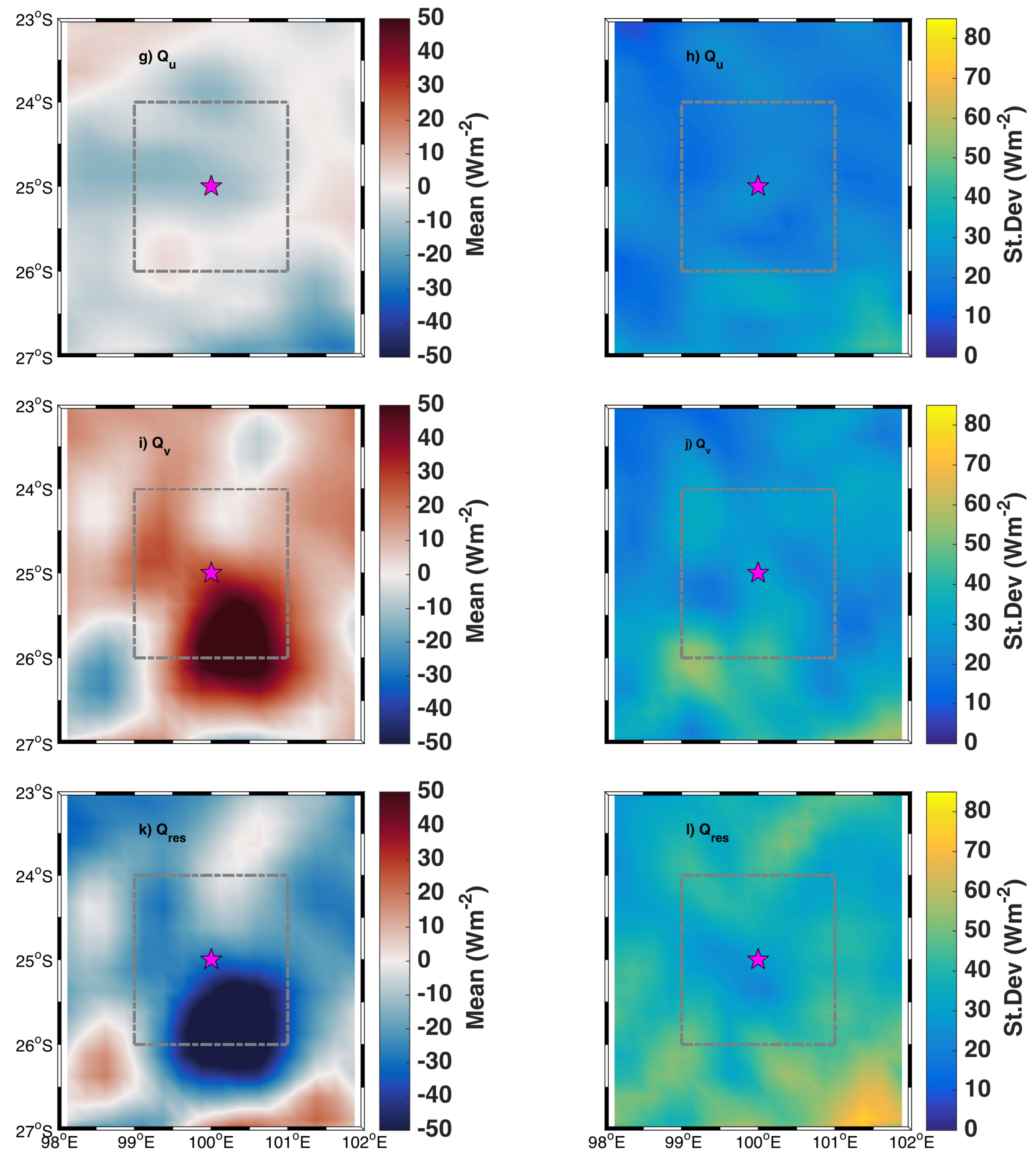
Figure15. 

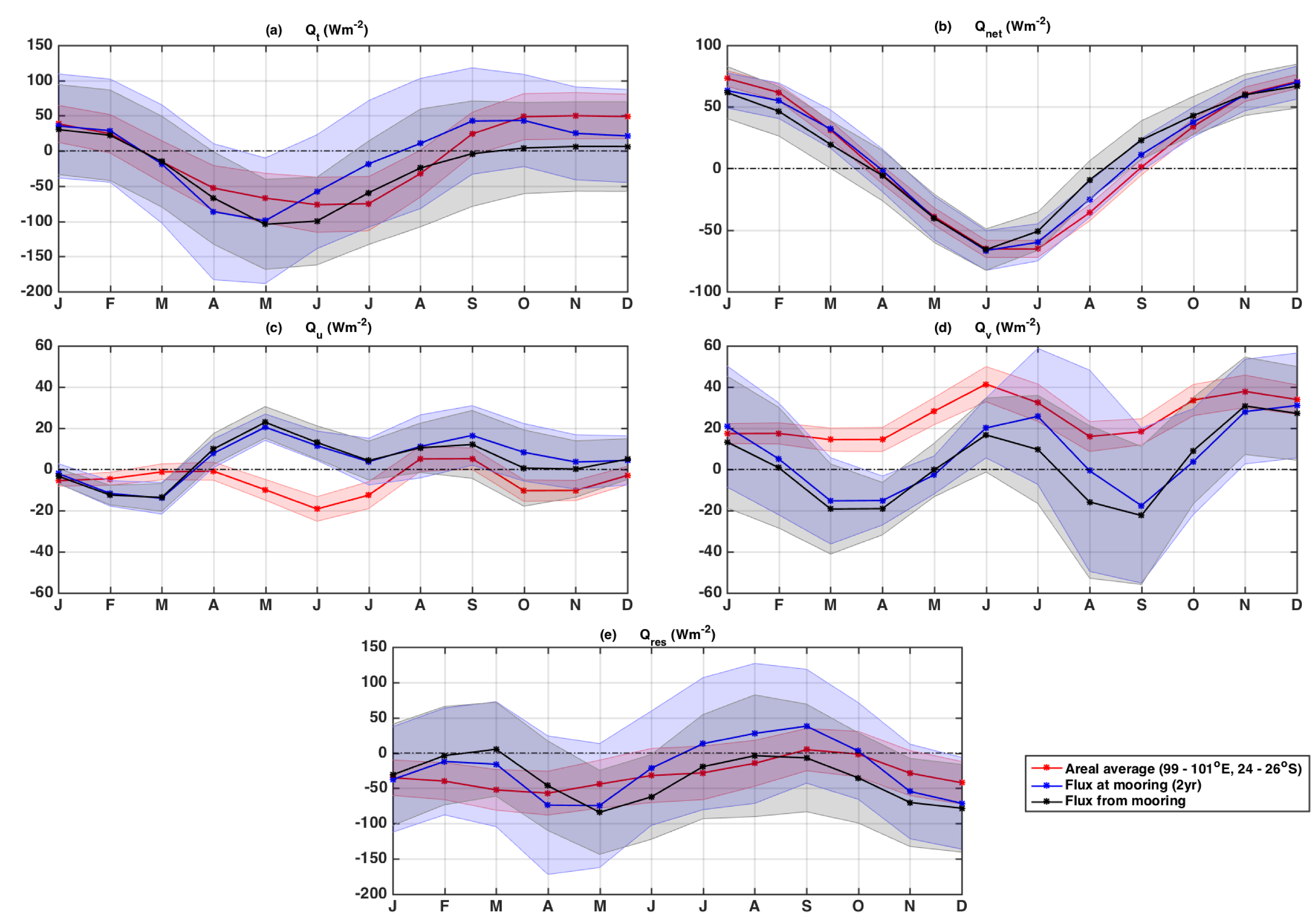
-"- Areal average $\left(99-101^{\circ} \mathrm{E}, 24-26^{\circ} \mathrm{S}\right)$
-"-Flux at mooring $(2 \mathrm{yr})$
-"-Flux from mooring 